\title{
Abrupt Summer Warming and Changes in Temperature Extremes over Northeast Asia Since the Mid-1990s: Drivers and Physical Processes
}

\author{
Buwen DONG*1, Rowan T. SUTTON ${ }^{1}$, Wei CHEN ${ }^{2}$, Xiaodong LIU ${ }^{3}$, Riyu LU ${ }^{2}$, and Ying SUN ${ }^{4}$ \\ ${ }^{1}$ National Centre for Atmospheric Science, Department of Meteorology, University of Reading, Reading RG6 6BB, UK \\ ${ }^{2}$ State Key Laboratory of Numerical Modeling for Atmospheric Sciences and Geophysical Fluid Dynamics, \\ Institute of Atmospheric Physics, Chinese Academy of Sciences, Beijing 100029 \\ ${ }^{3}$ Institute of Earth Environment, Chinese Academy of Sciences, Xi'an 710061 \\ ${ }^{4}$ National Climate Center, China Meteorological Administration, Beijing 100081
}

(Received 15 December 2015; revised 29 April 2016; accepted 3 June 2016)

\begin{abstract}
This study investigated the drivers and physical processes for the abrupt decadal summer surface warming and increases in hot temperature extremes that occurred over Northeast Asia in the mid-1990s. Observations indicate an abrupt increase in summer mean surface air temperature (SAT) over Northeast Asia since the mid-1990s. Accompanying this abrupt surface warming, significant changes in some temperature extremes, characterized by increases in summer mean daily maximum temperature (Tmax), daily minimum temperature (Tmin), annual hottest day temperature (TXx), and annual warmest night temperature (TNx) were observed. There were also increases in the frequency of summer days (SU) and tropical nights (TR). Atmospheric general circulation model experiments forced by changes in sea surface temperature (SST)/ sea ice extent (SIE), anthropogenic greenhouse gas (GHG) concentrations, and anthropogenic aerosol (AA) forcing, relative to the period 196493, reproduced the general patterns of observed summer mean SAT changes and associated changes in temperature extremes, although the abrupt decrease in precipitation since the mid-1990s was not simulated. Additional model experiments with different forcings indicated that changes in SST/SIE explained $76 \%$ of the area-averaged summer mean surface warming signal over Northeast Asia, while the direct impact of changes in GHG and AA explained the remaining $24 \%$ of the surface warming signal. Analysis of physical processes indicated that the direct impact of the changes in AA (through aerosolradiation and aerosol-cloud interactions), mainly related to the reduction of AA precursor emissions over Europe, played a dominant role in the increase in TXX and a similarly important role as SST/SIE changes in the increase in the frequency of SU over Northeast Asia via AA-induced coupled atmosphere-land surface and cloud feedbacks, rather than through a direct impact of AA changes on cloud condensation nuclei. The modelling results also imply that the abrupt summer surface warming and increases in hot temperature extremes over Northeast Asia since the mid-1990s will probably sustain in the next few decades as GHG concentrations continue to increase and AA precursor emissions over both North America and Europe continue to decrease.
\end{abstract}

Key words: surface warming, temperature extremes, global climate model, anthropogenic greenhouse gas, anthropogenic aerosol, SST/SIE, Northeast Asia, mid-1990s

Citation: Dong, B. W., R. T. Sutton, W. Chen, X. D. Liu, R. Y. Lu, and Y. Sun, 2016: Abrupt summer warming and changes in temperature extremes over Northeast Asia since the mid-1990s: Drivers and physical processes. Adv. Atmos. Sci., 33(9), 1005-1023, doi: 10.1007/s00376-016-5247-3.

\section{Introduction}

During the 20th century the global averaged surface air temperature (SAT) showed an unequivocal warming due to anthropogenic as well as natural causes (e.g., Kosaka and Xie, 2013; Trenberth et al., 2014; Steinman et al., 2015). Distinguishing between forced and natural variability and understanding the drivers are an essential step in developing

\footnotetext{
* Corresponding author: Buwen DONG

Email: b.dong@ reading.ac.uk
}

robust climate predictions and climate risk assessments. On multidecadal timescales, previous studies indicate that the North Atlantic and Pacific oceans are the key drivers of internal variability in Northern Hemisphere temperatures (e.g., Kosaka and Xie, 2013; Kamae et al., 2014a; Trenberth et al., 2014; Steinman et al., 2015).

Climate variability and change impose enormous challenges for China, with its rapidly developing economy and large population. Much of the rainfall and extreme climate conditions over the region in summer are associated with the East Asian summer monsoon (EASM). During the sec- 
ond half of the 20th century, the EASM circulation underwent a weakening tendency, which was characterized by a decreasing lower-tropospheric southwesterly wind and an increasing sea level pressure (SLP) over East Asia. Associated with the weakened EASM circulation were increases in precipitation over the middle and lower reaches of the Yangtze River valley and decreases over northern China, exhibiting a so-called "southern-flood-northern-drought" (SFND) pattern (e.g., Ding et al., 2008, 2009; Zhao et al., 2010; Huang et al., 2013; Wang et al., 2013, Zhao et al., 2014, Han et al., 2015; Ueda et al., 2015). Also accompanying the weakening EASM circulation were changes in seasonal mean SAT and temperature extremes over China and a large domain of Northeast Asia, and an increase in the frequency of dry spells and droughts (Ren et al., 2010; Wei and Chen, 2011; Li et al., 2012, Qi and Wang, 2012; Wang et al., 2012; Wen et al., 2013; Chen and Lu, 2014; Gao et al., 2014a, 2014b; Qian et al., 2014; Song et al., 2014; Sun et al., 2014; Yang et al., 2014).

Previous attribution studies suggest that the changes in SSTs, GHG concentrations, and AA precursor emissions through aerosol-radiation and aerosol-cloud interactions are all important factors for the SFND pattern and associated drought over North and northeastern China (e.g., Kwon et al., 2007; Feng and Hu, 2008; Kosaka and Xie, 2013; Andrews, 2014; Gao et al., 2014a, 2014b; Kamae et al., 2014a, 2014b; Qian et al., 2014; Song et al., 2014; Trenberth et al., 2014; Urabe and Maeda, 2014; Folini and Wild, 2015; Ueda et al., 2015; Wilcox et al., 2015; Zhang and Zhou, 2015). Previous studies have also revealed that decadal climate variability over East Asia is associated with low-frequency SST variability over the Pacific Ocean (e.g., Kwon et al., 2007, Kosaka and Xie, 2013; Kamae et al., 2014a; Trenberth et al., 2014; Ueda et al., 2015) and Atlantic Ocean (Feng and Hu, 2008; Kamae et al., 2014a; Qian et al., 2014) via atmospheric teleconnections. Using AGCM simulations, Andrews (2014) found that changes in SST/SIE contributed about $60 \%$ of the summer land warming trends during 1979-2008 in the Northern Hemisphere, while the direct radiative impact of changes in anthropogenic forcings contributed about $40 \%$ and was an important factor for reproducing the recent Northern Hemisphere continental warming. Kamae et al. (2014a) demonstrated that the direct warming effect due to anthropogenic forcing and indirect warming effect via increased SST are important for the recent land surface warming and increased frequency of hot summers over the midlatitude Northern Hemisphere.

East Asia is under both local and non-local influences of AA (e.g., Cowan and Cai, 2011; Dong et al., 2016a). The study of Cowan and Cai (2011) indicated that Asian aerosols lead to a weakening of the EASM through aerosol-radiation and aerosol-cloud interactions (e.g., Twomey, 1977; Rosenfeld et al., 2008). The addition of non-Asian aerosols leads to further suppression of monsoon rainfall over Asia, highlighting the importance of the non-Asian aerosols in changes in Asian summer monsoon circulation and rainfall across Asia. Dong et al. (2016a) indicated that aerosol emissions over
Asia and Europe both influence the thermal contrast between Asian land and the western North Pacific, leading to a weakening EASM, but through very different processes. Due to the implementation of air quality legislation, AA precursor emissions over both Europe and North America have continuously declined since the 1980s (Smith et al., 2011; Kühn et al., 2014). In contrast, over the same period, aerosol emissions in China and India have continuously increased (Lu et al., 2011).

The SFND pattern and warming over Northeast Asia have emerged particularly strongly since the mid-1990s (Kwon et al., 2007; Chen and Lu, 2014; Han et al., 2015; Ueda et al., 2015). This is roughly coincident with rapid increases in aerosol emissions from China and India and decreases in aerosol emissions from North America and Europe. Although previous studies have demonstrated the effects of recent decadal SST variation on decadal change in summer precipitation and surface warming over East Asia (e.g., Feng and Hu, 2008; Han et al., 2015; Ueda et al., 2015), a comprehensive and quantitative understanding of the drivers and physical processes governing the SFND pattern, and the associated changes in temperature extremes over Northeast Asia, is still lacking.

The main aims in carrying out this study were to understand what has caused the observed rapid changes in SAT and increases in hot temperature extremes over Northeast Asia since the mid-1990s. In particular, we sought to quantify the relative roles of changes in (1) SST/SIE, (2) anthropogenic GHG forcing through its direct impact, and (3) AA forcing through aerosol-radiation and aerosol-cloud interactions, in shaping these regional changes in surface warming and temperature extremes, by performing a set of numerical experiments using the atmospheric component of HadGEM3. It is important to stress that we did not address the anthropogenic contribution of changes in GHG concentrations and AA precursor emissions to observed SST/SIE changes; rather, we considered the SST/SIE changes as an independent forcing factor.

The structure of the paper is as follows: Section 2 describes the observed changes since the mid-1990s over Northeast Asia. In section 3, the model experiments and model climatology are described briefly. Section 4 presents the simulated changes in response to different forcings. Section 5 elucidates the physical processes involved in the responses. Conclusions are given in section 6 .

\section{Observed changes over Northeast Asia since the mid-1990s}

\subsection{Observational data sets}

Observational monthly mean datasets used in this study were: the University of Delaware (UD) land SAT and precipitation v3.01 from 1901 to 2010 (Legates and Willmott, 1990a, 1990b); CRU TS3.21 SAT and precipitation from 1901 to 2013 , on a $0.5^{\circ} \times 0.5^{\circ}$ grid (Harris et al., 2014); NOAA's Precipitation Reconstruction over Land (PREC/L) 
from 1948 to 2013 , on a $1^{\circ} \times 1^{\circ}$ grid (Chen et al., 2002); GPCP v2.2 precipitation from 1979 to 2013 , on a $2.5^{\circ} \times 2.5^{\circ}$ grid (Adler et al., 2003); and NASA's GISTEMP from 1880 to 2013 , on a $2^{\circ} \times 2^{\circ}$ grid (Hansen et al., 2010). The monthly mean SSTs used in the model experiments were based on HadISST from 1871 to 2013 , on a $1^{\circ} \times 1^{\circ}$ grid Rayner et al., 2003). Monthly mean variables of the NCEP-NCAR reanalysis from 1979 to 2013 (Kalnay et al., 1996) were also used. Temperature extremes used in the observational analysis were from the HadEX2 dataset (Donat et al., 2013).

\subsection{Observed changes}

Following the work of Chen and Lu (2014), a number of temperature and precipitation indices averaged in a rectangular region $\left(40^{\circ}-50^{\circ} \mathrm{N}, 90^{\circ}-130^{\circ} \mathrm{E}\right)$ over Northeast Asia during the summer (June-September, JJAS) or annual mean were calculated. Figure 1 shows the temporal evolution of indices of SAT, precipitation, and a number of temperature extreme anomalies, relative to the climatology, averaged over the whole time series. These time series clearly exhibit decadal to multidecadal variability, with cooling and wet conditions, from the 1960s to the 1980s, which might have been associated with North Atlantic cooling (e.g., Liu and Chiang, 2012). One of the most important features revealed is the abrupt surface warming since the mid-1990s (Fig. 1a). This is in line with the findings of Chen and Lu (2014), who demonstrated that the abrupt point for the decadal shift was 1993/94. We therefore compared the changes during the recent 16 years (1996-2011) relative to the early period of 1964-93 and found that the area-averaged SAT changes over Northeast Asia ranged from $1.21^{\circ} \mathrm{C}$ to $1.27^{\circ} \mathrm{C}$, from four datasets. Accompanying the abrupt increase in the summer mean SAT was a decrease in local precipitation (Fig. 1b), and the area mean decreases ranged from -0.22 to $-0.18 \mathrm{~mm} \mathrm{~d}^{-1}$, about $10 \%$ of the climatological precipitation (e.g., Chen and Lu, 2014; Wilcox et al., 2015).

The rapid summer mean surface warming and drying over Northeast Asia since the mid-1990s accompanied rapid changes in temperature extremes (Figs. 1c-e). The changes in these temperature extremes indicate a rapid increase in summer mean Tmax (daily maximum temperature), Tmin (daily minimum temperature), TXx (annual hottest day temperature), and TNx (annual warmest night temperature). However, the change in the diurnal temperature range (DTR) was relatively small (Fig. 1c). Figure 1e also shows a rapid increase (by 14 and 6 days, respectively) in the frequency of summer days (SU; annual number of days when Tmax $>$ $25^{\circ} \mathrm{C}$ ) and tropical nights [TR; annual number of days when Tmin $>20^{\circ} \mathrm{C}$; see Donat et al. (2013)] over Northeast Asia.

The spatial patterns of changes in SAT and precipitation between the recent period and the early period are illustrated in Fig. 2. The SAT change shows a warming everywhere over the Eurasian continent (e.g., Tang et al., 2012), with the largest warming over Northeast Asia. Changes in precipitation are characterized by a decrease of $0.2-0.8 \mathrm{~mm}$ $\mathrm{d}^{-1}$ over Northeast Asia, and an increase of $0.2-1.6 \mathrm{~mm} \mathrm{~d}^{-1}$ over South China and the lower reaches of the Yangtze River (a) SAT indices in JJAS

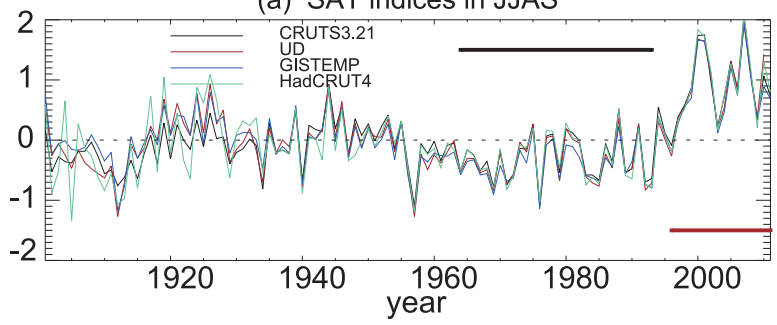

(b) Precipitation indices in JJAS

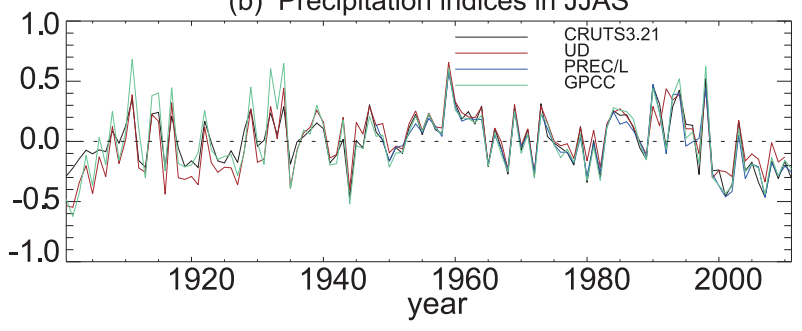

(c) Tmax, Tmin, and DTR in JJAS (CRUT3.21)

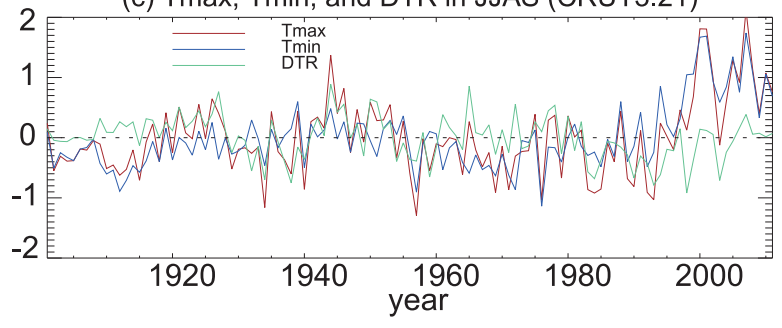

(d) Extreme temperature indices TXx and TNx (HadEX2)

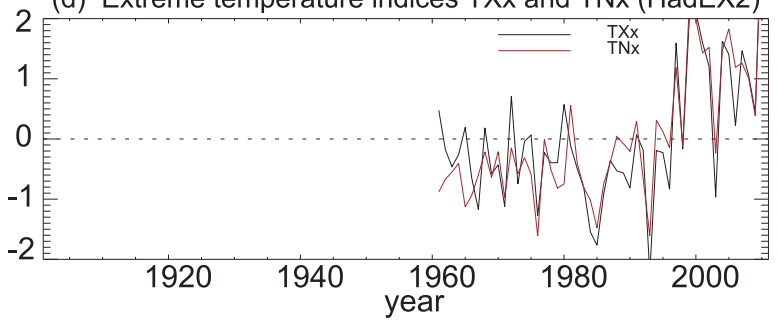

(e) Summer days and tropical nights (HadEX2)

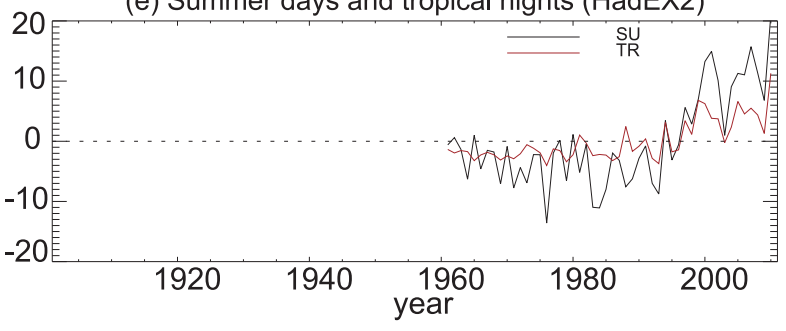

Fig. 1. Time series of summer (JJAS) or annual mean anomalies relative to the climatology (mean of the whole period) averaged over Northeast Asia $\left[\left(40^{\circ}-50^{\circ} \mathrm{N}, 90^{\circ}-130^{\circ} \mathrm{E}\right)\right.$; red box in Fig. 2b]: (a) SAT (units: ${ }^{\circ} \mathrm{C}$ ); (b) precipitation (units: $\mathrm{mm} \mathrm{d}^{-1}$ ); (c) Tmax, Tmin and DTR (units: ${ }^{\circ} \mathrm{C}$ ); (d) TXx and TNx (units: ${ }^{\circ} \mathrm{C}$ ); and (e) frequency of SU and TR (units: $\mathrm{d} \mathrm{yr}^{-1}$ ). Black and red range bars in (a) indicate the early period of 1964-93 and the recent period of 1996-2011, respectively.

valley; and this is the SFND pattern-related to the weakening of the EASM-revealed in many previous studies (e.g. Ding et al., 2008, 2009; Zhao et al., 2010; Wang et al., 2013; Chen and Lu, 2014).

The spatial patterns of changes in some temperature ex- 
(a) SAT change in JJAS (CRUTS3.21)

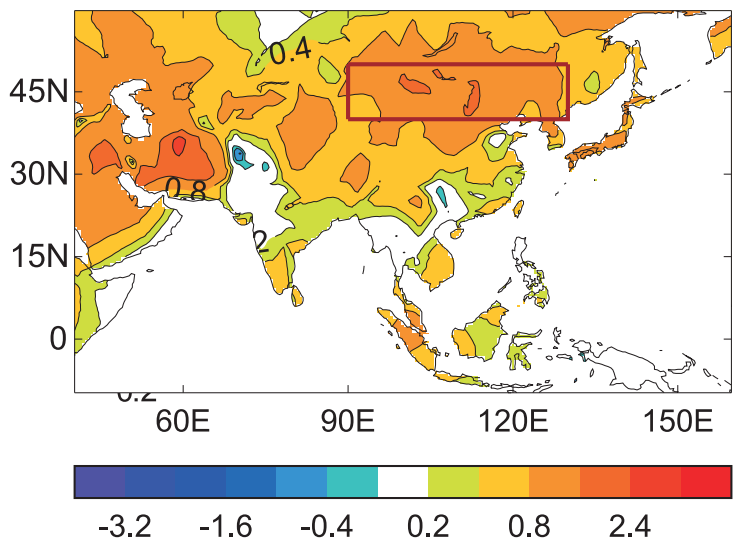

(b) Precipitation change in JJAS (CRUTS3.21)

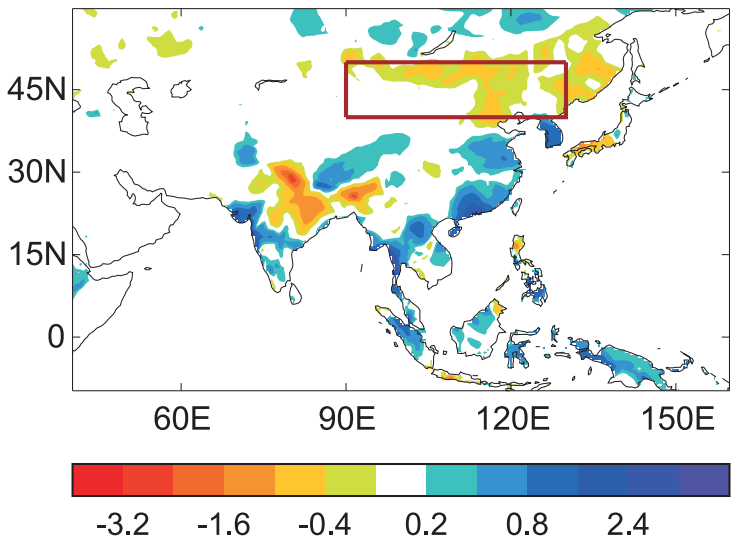

Fig. 2. Spatial patterns of differences in (a) SAT (units: ${ }^{\circ} \mathrm{C}$ ) and (b) precipitation (units: $\mathrm{mm} \mathrm{d}^{-1}$ ) between the recent period of 1996-2011 and the early period of 1964-93. The thick red boxes highlight Northeast Asia, where some area-averaged indices were calculated.

tremes during the recent period relative to the early period are illustrated in Fig. 3. The main features of change are the increase in both Tmax and Tmin since the mid-1990s in most regions over the Eurasian continent. However, the changes in Tmax and Tmin show large spatial variations (Figs. 3a and b). Tmax changes show a large increase over Eastern Europe and Northeast Asia, and a relatively small increase over East China. Meanwhile, Tmin changes show a relatively uniform increase in a large domain over Asia. As a result, the changes in DTR indicate very large spatial variations, with an increase over Eastern Europe, small changes over Northeast Asia (e.g., Shen et al., 2014), and a decrease over East China. The large decrease in DTR over the Tibetan Plateau is not consistent with the changes in Chinese station data (e.g., You et al., 2015), and this indicates large uncertainty in the temperatureextreme changes in this data-sparse region. Changes in TXx and TNx (Figs. 3d and e) between the two periods show a localized maximum (about $1.8^{\circ} \mathrm{C}$ ) over Northeast Asia. The changes in frequency of SU and TR also show an increase, with a local maximum of about 12-15 days and 2-8 days over Northeast Asia (Figs. 3f and g).

What has caused these observed rapid changes in summer mean SAT and increases in temperature extremes over Northeast Asia? Understanding the drivers of these changes is key for predicting climate and extreme events in the next few decades for China and Northeast Asia. By using the atmospheric component of HadGEM3 in a series of model experiments with different forcings, we investigated the drivers and physical processes for these observed changes over Northeast Asia since the mid-1990s. The findings are reported in the following sections.

\section{Model experiments and model climatology}

\subsection{Model and model experiments}

Since the mid-1990s, there have been changes in the potential drivers of climate over Northeast Asia. Global-mean SST has warmed relative to the early period of 1964-93 (Fig. 4a). SST anomalies are characterized by regional patterns associated with a positive phase of the AMO (Atlantic Multidecadal Oscillation) and a negative phase of the PDO (Pacific Decadal Oscillation) (e.g., Kosaka and Xie, 2013; Kamae et al., 2014a; Steinman et al., 2015). There have been significant increases in anthropogenic GHG concentrations (11\% increase in $\mathrm{CO}_{2}, 18 \%$ increase in $\mathrm{CH}_{4}$, and $6 \%$ increase in $\mathrm{N}_{2} \mathrm{O}$ ) and significant changes in AA precursor emissions. The changes in annual mean sulfur dioxide emissions- the most important aerosol precursor-show decreases over Europe and North America and increases over Asia (Fig. 4b).

A set of climate model experiments were run to assess the extent that the observed rapid increases in SAT and changes in temperature extremes over Northeast Asia since the mid-1990s can be reproduced when the model is forced by changes in SST/SIE, GHG and AA forcings, and to quantify the relative roles of individual forcing factors. The model used was HadGEM3-A (Hewitt et al., 2011), with a horizontal resolution of $1.875^{\circ}$ longitude by $1.25^{\circ}$ latitude and 85 vertical levels. The model includes an interactive tropospheric chemistry scheme with eight aerosol species and considers both aerosol-radiation and aerosol-cloud interactions. A detailed description of the tropospheric chemistry scheme was documented in Bellouin et al. (2013). The experiments, summarized in Table 1, were carried out and documented in detail in Dong et al. (2016b). The recent recovery of Sahel rainfall amounts was investigated in Dong and Sutton (2015), while the rapid summer surface warming and changes in temperature extremes since the mid-1990s over Western Europe were investigated in Dong et al. (2016b), using the same set of experiments. The response to a particular forcing was diagnosed by the mean difference between a pair of model experiments (one that included and one that excluded that forcing), based on the last 25 years of each experiment. The response to changes in all forcings was estimated by the mean difference between experiments ALL and CONTROL, and the response to changes in SST/SIE by the difference between SSTONLY and CONTROL. The response to changes in AA forcing was estimated by the mean difference 
(a) Tmax change in JJAS (CRUTS3.21)

(b) Tmin change in JJAS (CRUTS3.21)

(c) DTR change in JJAS (CRUTS3.21)
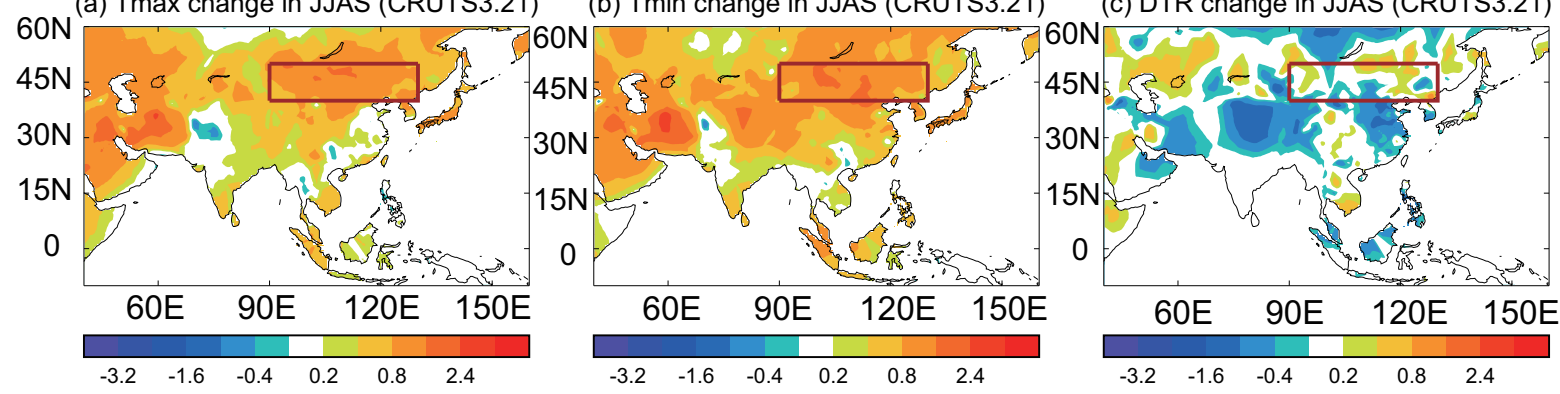

(d) Change in TXx (HadEX2)

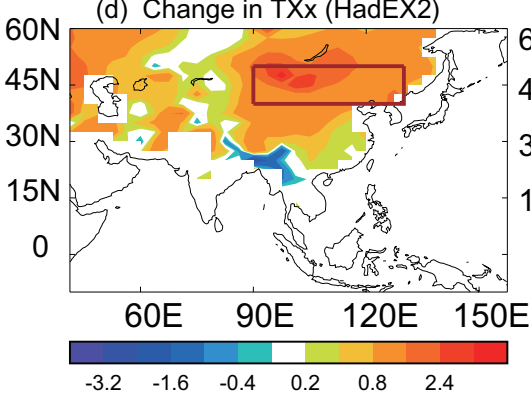

(e) Change in TNx (HadEX2)

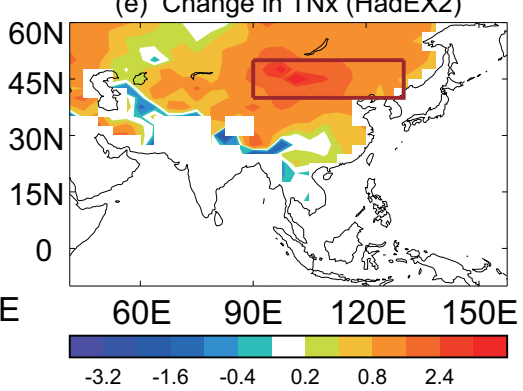

(f) Change in summer days (HadEX2)

(g) Change in tropical nights (HadEX2)
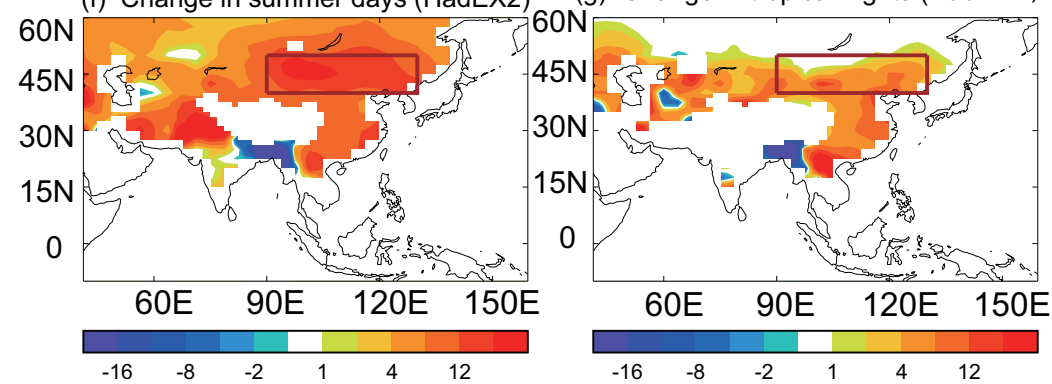

Fig. 3. Spatial patterns of differences in some temperature extremes between the recent period of 1996-2011 and the early period of 1964-93: (a) Tmax; (b) Tmin; (c) DTR; (d) TXx; (e) TNx; (f) SU; and (g) TR. The units for SAT, Tmax, Tmin, DTR, $\mathrm{TXx}$ and $\mathrm{TNx}$ are ${ }^{\circ} \mathrm{C}$. The units for SU and TR are $\mathrm{d} \mathrm{yr}^{-1}$. The thick red boxes highlight Northeast Asia.

Table 1. Summary of numerical experiments [reprinted from Dong et al. (2016b)].

\begin{tabular}{|c|c|}
\hline Experiment & Boundary conditions \\
\hline CONTROL & $\begin{array}{l}\text { Monthly climatological SST and SIE averaged over } \\
\text { the period 1964-93, using HadISST (Rayner et } \\
\text { al., 2003), with anthropogenic GHG concentra- } \\
\text { tions set at mean values over the same period, and } \\
\text { AA precursor emissions (Lamarque et al., 2010) } \\
\text { at mean values over the period 1970-93. }\end{array}$ \\
\hline ALL & $\begin{array}{l}\text { Monthly climatological SST/SIE averaged over the } \\
\text { period 1996-2011, with GHG concentrations set } \\
\text { at mean values over the period 1996-2009, and } \\
\text { AA precursor emissions at mean values over the } \\
\text { period 1996-2010. }\end{array}$ \\
\hline SSTGHG & $\begin{array}{l}\text { Monthly climatological SST/SIE averaged over the } \\
\text { period 1996-2011, with GHG concentrations set } \\
\text { at mean values over the period 1996-2009, but } \\
\text { with AA precursor emissions at mean values over } \\
\text { the period 1970-93. }\end{array}$ \\
\hline SSTONLY & $\begin{array}{l}\text { Monthly climatological SST/SIE averaged over the } \\
\text { period 1996-2011, with GHG concentrations and } \\
\text { AA precursor emissions the same as in CON- } \\
\text { TROL. }\end{array}$ \\
\hline
\end{tabular}

between experiments ALL and SSTGHG, while the response to changes in GHG by the difference between SSTGHG and SSTONLY, with the assumption that the responses to individual forcings combined linearly. Seasonal mean changes for summer (JJAS) were the main focus of study. The statistical significance of summer mean changes and the $90 \%$ confidence intervals of the some area-averaged changes over Northeast Asia, in both observations and model experiments, in response to different forcings, were assessed using the twotailed Student's $t$-test.

\subsection{Model-simulated climatology}

This section compares the model-simulated climatological features of CONTROL with observed features (Fig. 5). Figures $5 \mathrm{a}$ and $\mathrm{b}$ show the SAT based on NCEP-NCAR reanalysis data (Kalnay et al., 1996) and observed precipitation based on GPCP (Adler et al., 2003), whereas Figs. 5c and d show the corresponding model-simulated SAT and precipitation.

In observations, the SAT pattern was characterized by strong meridional temperature gradients around $45^{\circ} \mathrm{N}$ over 
(a) SST (1996-2011 minus 1964-93, HadISST)

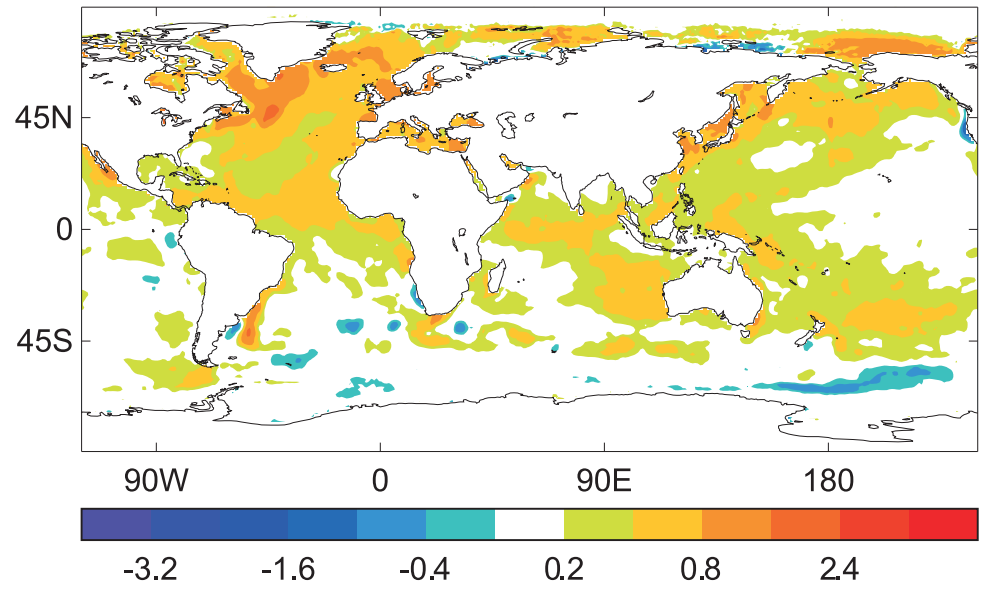

(b) Annual sulfur dioxide (1996-2010 minus 1970-93)

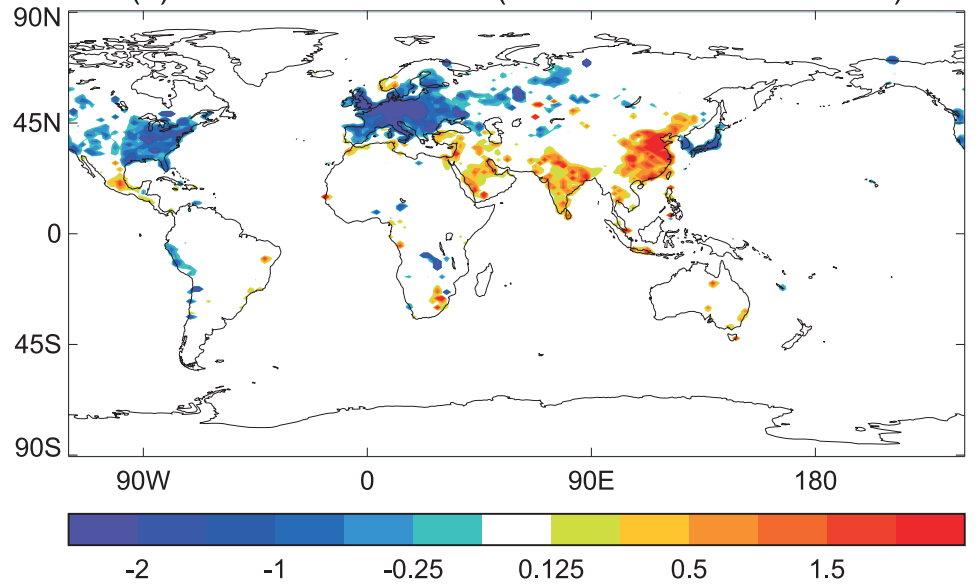

Fig. 4. Differences in (a) global SST in JJAS (units: ${ }^{\circ} \mathrm{C}$ ), based on HadISST, between the two periods of 1996-2011 and 1964-93, and (b) annual mean sulfur dioxide emissions (units: $\mathrm{g} \mathrm{m}^{-2} \mathrm{yr}^{-1}$ ) between 1996-2010 and 1970-93. [Reprinted from Dong et al., (2016b)]

East Asia (Fig. 5a). The model reproduced the large-scale pattern of SAT well (Fig. 5c). Observed precipitation showed local maxima over the Western Ghats, Indochina, and the western North Pacific (Fig. 5b). The model simulation showed relatively weak precipitation over the Western Ghats, central India, and a large area over the western Bay of Bengal (Fig. $5 \mathrm{~d}$ ), in comparison with observations. However, the model overestimated precipitation over the western equatorial Indian Ocean and the Himalayan foothills (Fig. 5d). Convection tends to develop preferentially over these regions due to the orographic impact as the low-level southwesterly flow hits the Himalayan foothills, and the large moisture and heat availability over the equatorial Indian Ocean. The overestimation of precipitation over the equatorial Indian Ocean appears to be an inherent feature of the Met Office Unified Model (Martin et al., 2010), and is also present in other versions of the Met Office Hadley Centre Global Environmental Model (Levine and Turner, 2012; Guo et al., 2013, Dong et al., 2016a). Despite these deficiencies, the simulated SAT and precipitation over Northeast Asia compared fairly well with observations, giving credibility for using the model to inves- tigate the response of regional climate over Northeast Asia to changes in different forcings.

\section{Model-simulated changes in response to dif- ferent forcings}

The spatial distributions of changes in summer mean SAT and precipitation in response to different forcings, together and individually, are given in Fig. 6. The model responses to changes in SST/SIE and anthropogenic forcings (Fig. 6a), relative to CONTROL, reproduced the general patterns of observed changes in summer mean SAT over the Eurasian continent, but the simulated warming was more uniform than observed (Fig. 2a). The response in the model of surface warming to changes in all forcings was predominantly due to SST/SIE changes, which were responsible for the general warming found over the low-to-middle latitude Eurasian continent, with a magnitude of $0.4^{\circ} \mathrm{C}-1.2^{\circ} \mathrm{C}$ (Fig. 6c), in which the recent warming of the North Atlantic might have played an important role (e.g., Feng and Hu, 2008; Steinman et al., 
(a) SAT in JJAS (NCEP)

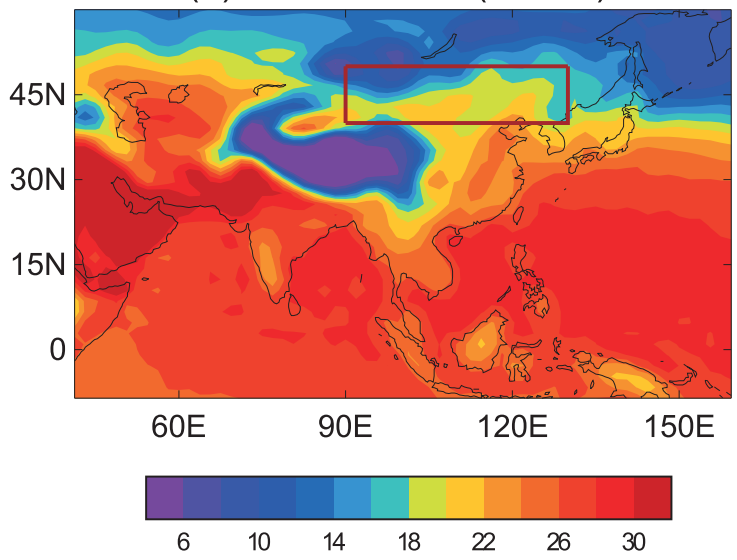

(c) SAT in JJAS (Model)

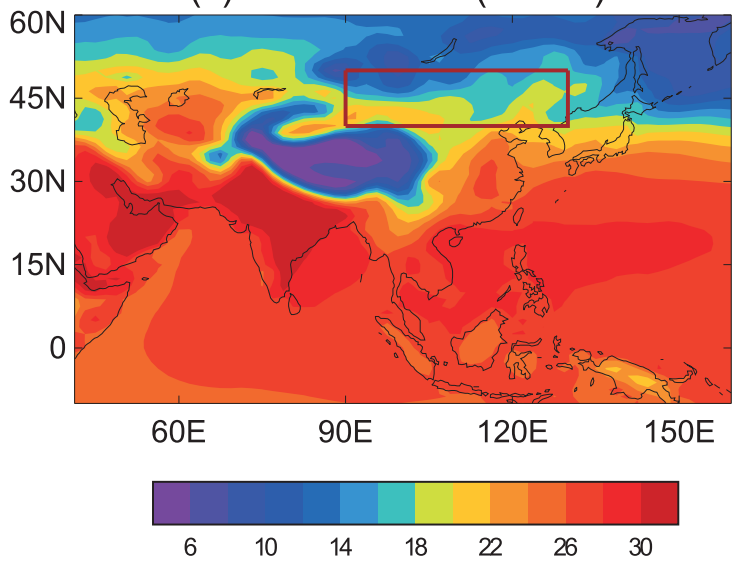

(b) Precipitation in JJAS (GPCP)

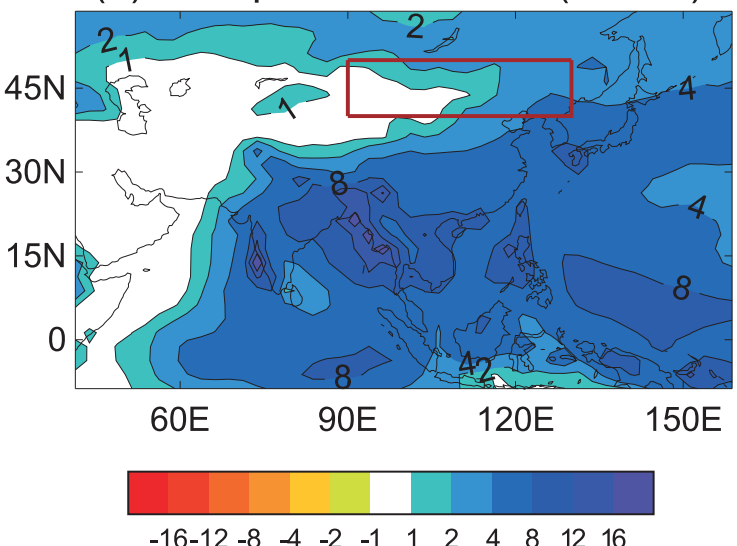

(d) Precipitation in JJAS (Model)

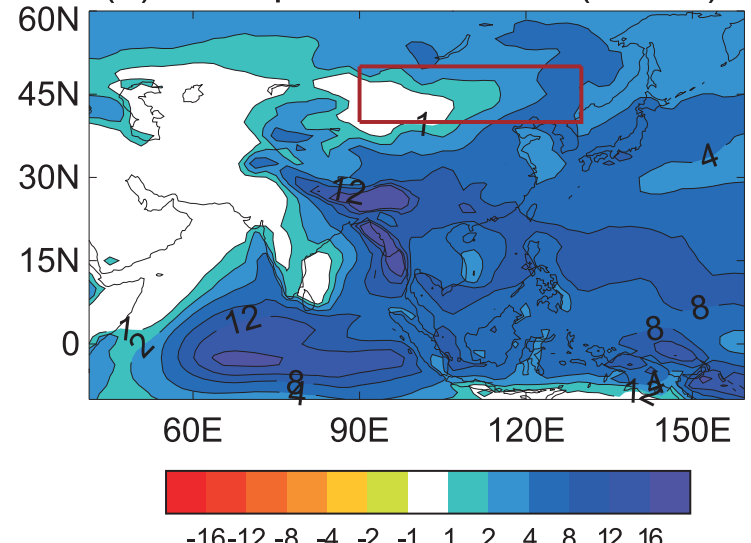

Fig. 5. Spatial patterns of the JJAS climatology for (a, c) SAT (units: ${ }^{\circ} \mathrm{C}$ ) and (b, d) precipitation (units: $\mathrm{mm} \mathrm{d}^{-1}$ ) in $(\mathrm{a}$, b) observations and (c, d) CONTROL. The thick red boxes highlight Northeast Asia.

2015). The changes in SAT due to aerosol forcing manifested as a band $\left(40^{\circ}-55^{\circ} \mathrm{N}\right)$ of positive anomalies extending from Europe to Northeast Asia, with a magnitude of $0.2^{\circ} \mathrm{C}-0.8^{\circ} \mathrm{C}$ (Fig. 6g); whereas, the direct impact of changes in GHG concentrations induced more localized warming over Europe, with weak warming over Northeast Asia (Fig. 6e). These results indicate that the direct impact of changes in anthropogenic GHG and AA changes plays an important role in midlatitude warming over the Eurasian continent, which is consistent with the recent studies of Kamae et al. (2014a) and Andrews (2014).

In response to changes in all forcings, the model simulated an increase in precipitation over Yangtze River basin, but did not reproduce the drying over Northeast Asia (Fig. 6b). Sperber et al. (2013) showed that current climate models still have biases in simulating Asian summer monsoon circulation and associated precipitation. The results presented in this paper, and those of Christidis et al. (2013) and of Wilcox et al. (2015), suggest that these biases need to be reduced in order for robust attribution of decadal change in precipitation over Asia to be obtained. Changes in GHG concentrations lead to wet conditions over East Asia and Northeast Asia (e.g., Song et al., 2014), while changes in AA precursor emissions lead to opposite changes (e.g., Wilcox et al., 2015).
Associated with a band of surface warming that resulted from AA changes was a band of reduced precipitation extending from Europe to Northeast Asia (Figs. 6g and h), implying a role of changes in non-local aerosol emissions for SAT and precipitation over Northeast Asia. This will be discussed in more detail in section 5 .

The responses of seasonal mean Tmax, Tmin and DTR to changes in different forcings, together and individually, are illustrated in Fig. 7. The model-simulated changes in response to all forcings showed an increase in both Tmax and Tmin over the Eurasian continent, in which the changes in Tmax were large over Eastern Europe but the Tmin changes showed a more or less uniform increase over the midlatitudes (Figs. $7 \mathrm{a}$ and $\mathrm{b}$ ). As a result, DTR changes showed an increase over Eastern Europe and a weak change over Northeast Asia (Fig. 7c), similar to the observed change (Fig. 3c), albeit the enhancement in DTR over Eastern Europe was overestimated in the model responses to changes in all forcings. Changes in SST/SIE led to an increase in both Tmax and Tmin over the Eurasian continent, with the increase in Tmin being larger than the increase in Tmax over Northeast Asia, and this led to a decrease in local DTR (Figs. 7d-f). The direct impacts of changes in GHG and AA forcings both led to more localized changes in Tmax and Tmin, with the GHG changes 
(a) SAT change in JJAS (All)

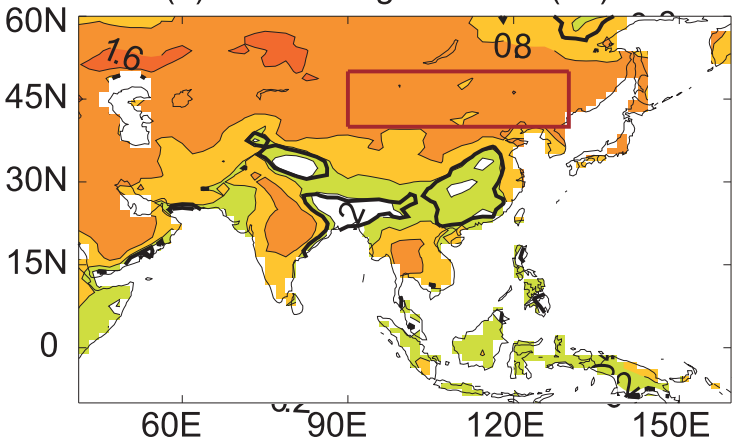

(c) SAT change in JJAS (SST)

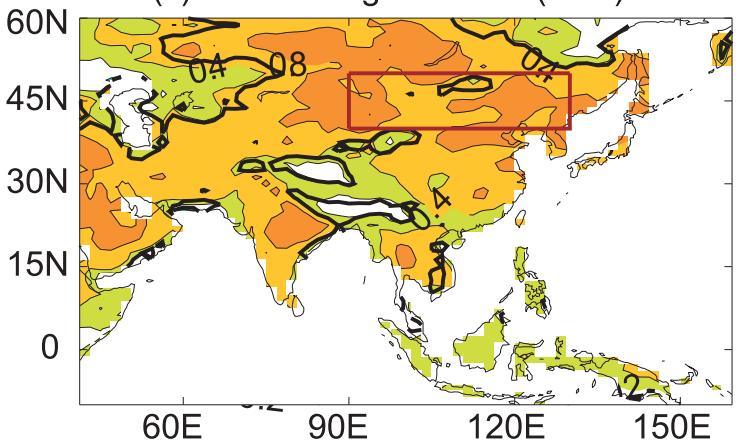

(e) SAT change in JJAS (GHG)

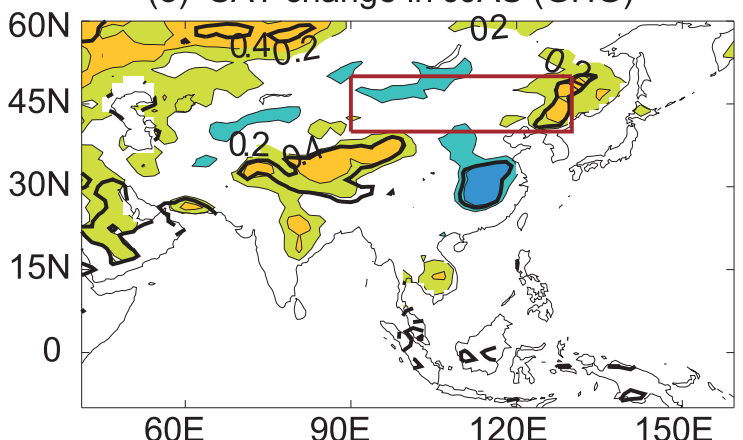

(g) SAT change in JJAS (aerosols)

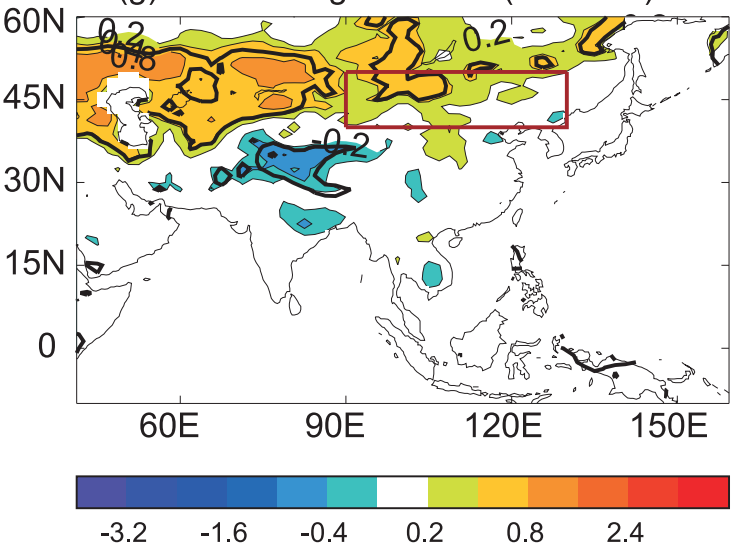

(b) Precipitation change in JJAS (All)

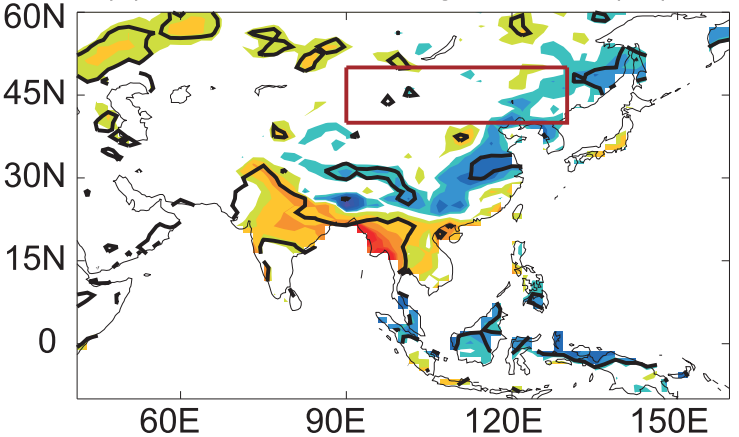

(d) Precipitation change in JJAS (SST)

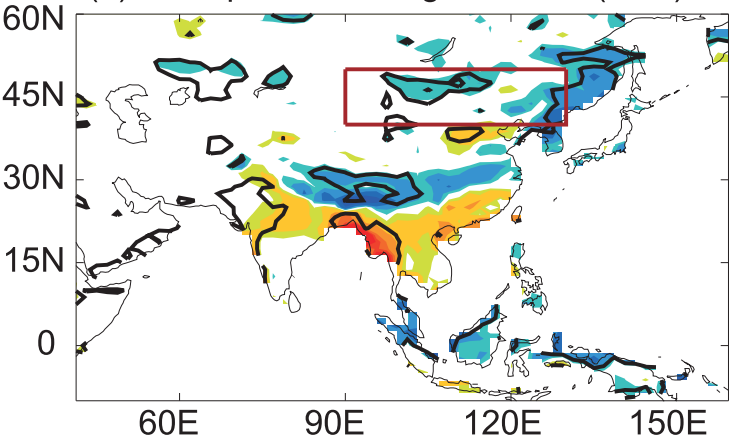

(f) Precipitation change in JJAS (GHG)

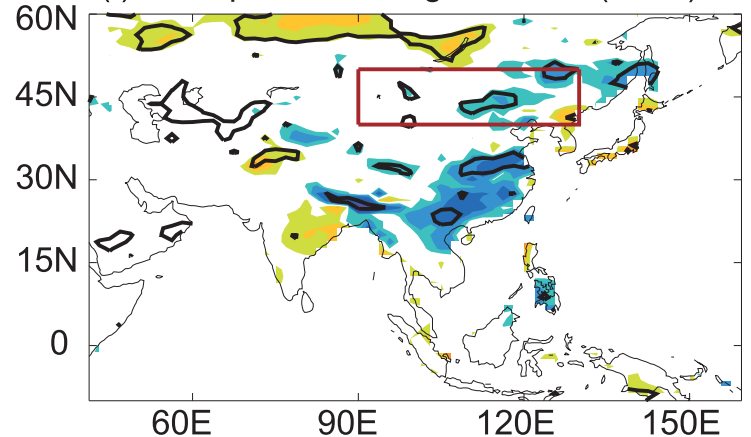

(h) Precipitation change in JJAS (aerosols)

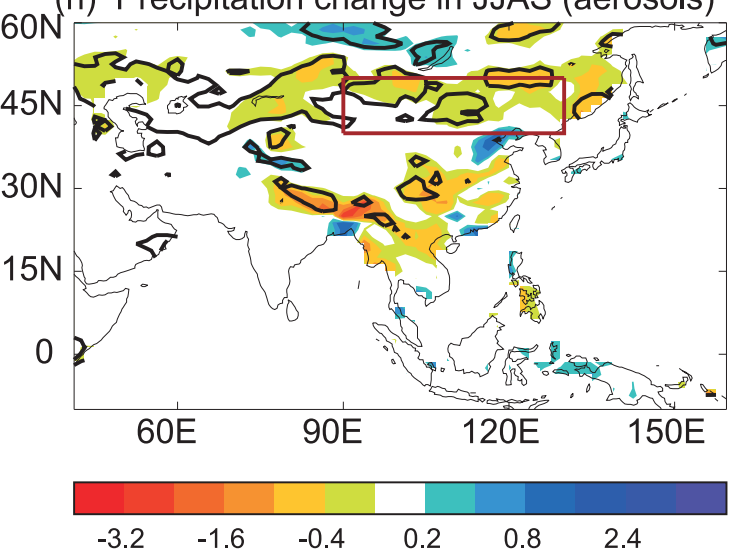

Fig. 6. Spatial patterns of summer mean (JJAS) SAT (units: ${ }^{\circ} \mathrm{C}$ ) (left panels) and precipitation (units: $\mathrm{mm} \mathrm{d}^{-1}$ ) (right panels) changes: (a, b) response forced by changes in SST/SIE, GHG concentrations, and AA precursor emissions (ALL minus CONTROL); (c, d) response to changes in SST/SIE (SSTONLY minus CONTROL); (e, f) response to changes in GHG concentrations (SSTGHG minus SSTONLY); and (g, h) response to changes in AA precursor emissions (ALL minus SSTGHG). Thick black lines highlight regions where the changes are statistically significant at the 90\% confidence level, based on a two-tailed Student's $t$-test. The thick red boxes highlight Northeast Asia. 
(a) Tmax change in JJAS (All)

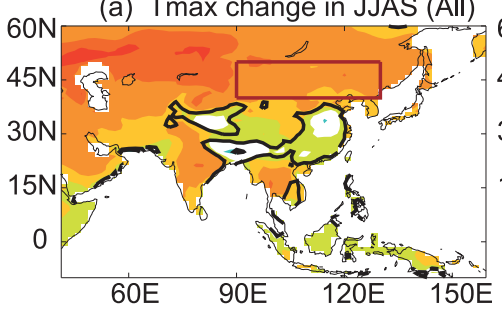

(d) Tmax change in JJAS (SST)

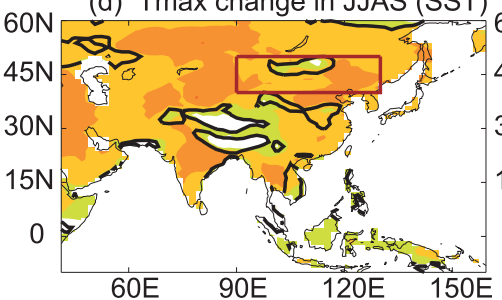

(g) Tmax change in JJAS (GHG)
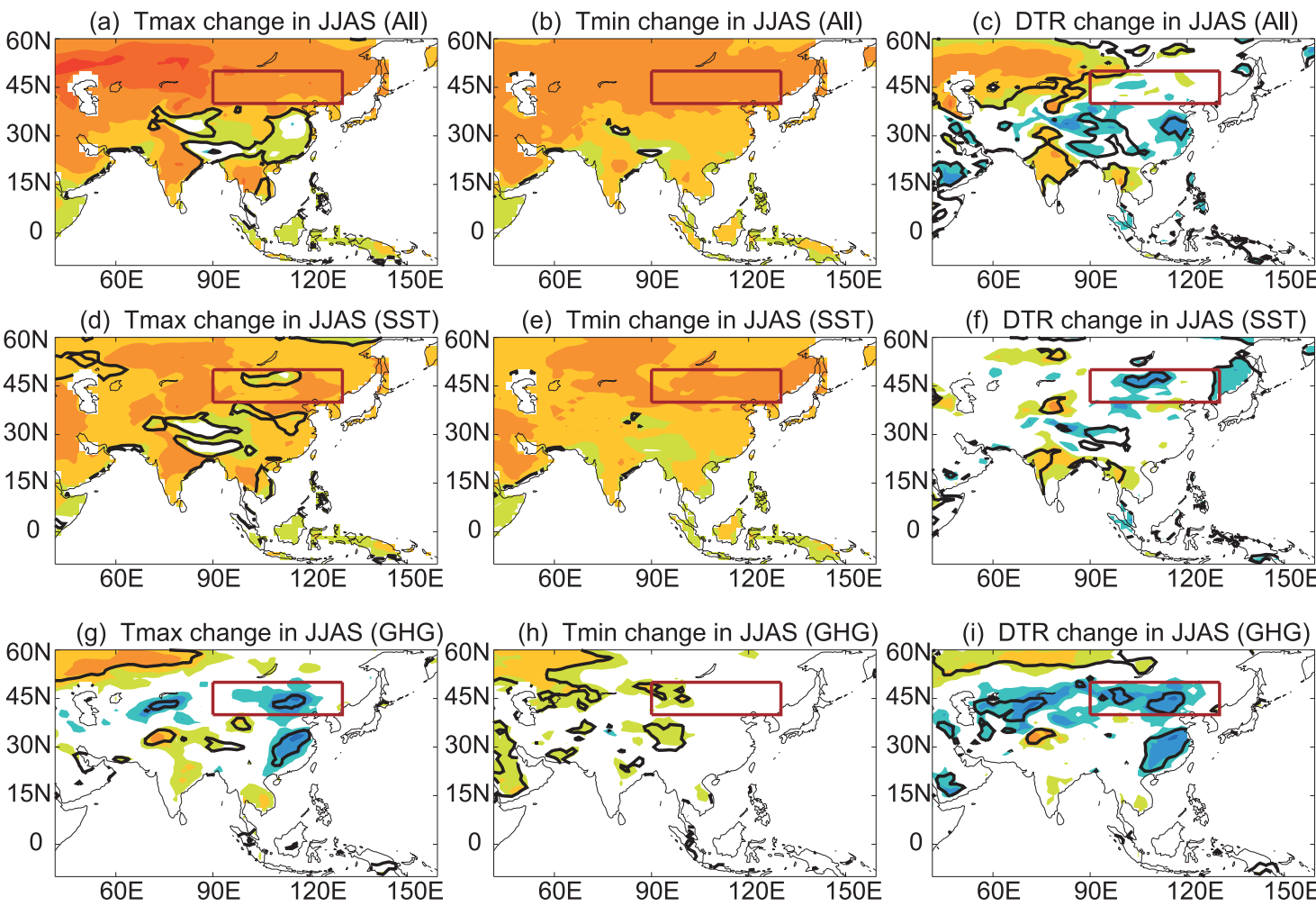

(e) Tmin change in JJAS (SST)
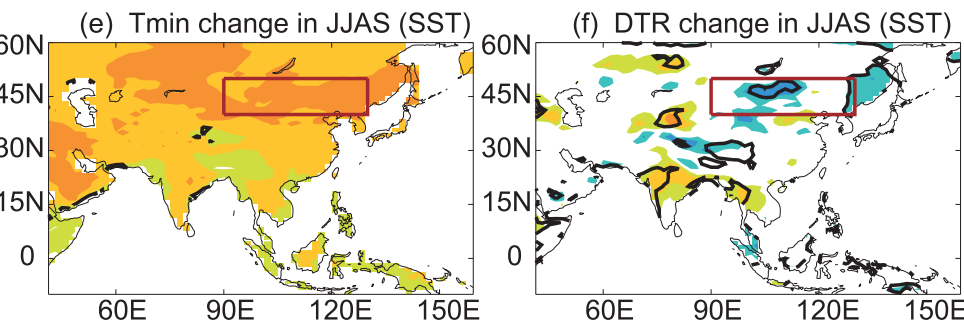

(i) DTR change in JJAS (GHG)
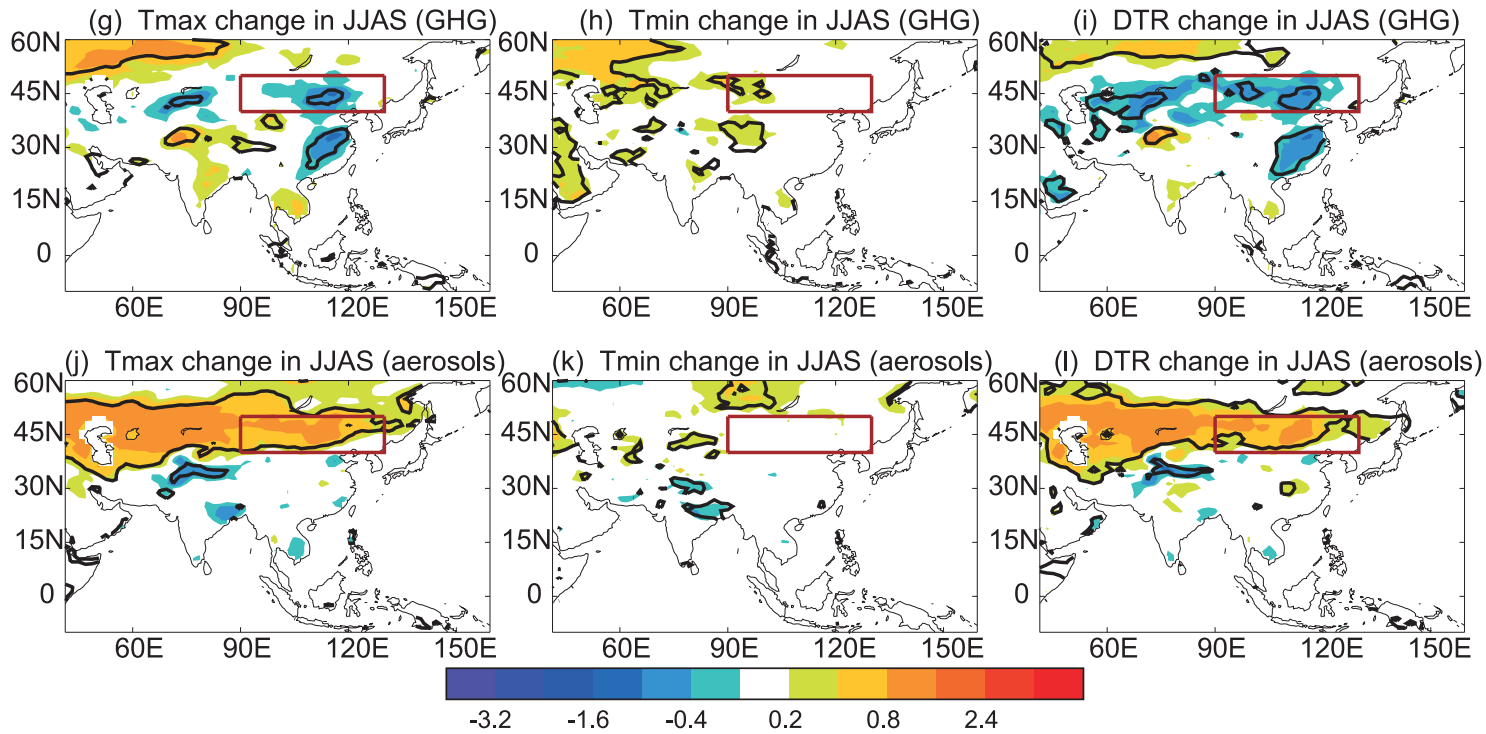

Fig. 7. Spatial patterns of summer mean responses for Tmax (left column), Tmin (middle column), and DTR (right column) (units: $\left.{ }^{\circ} \mathrm{C}\right):(\mathrm{a}-\mathrm{c})$ response forced by changes in SST/SIE, GHG concentrations, and AA precursor emissions (ALL minus CONTROL); (d-f) response to changes in SST/SIE (SSTONLY minus CONTROL); (g-i) response to the changes in GHG concentrations (SSTGHG minus SSTONLY); and (j-1) response to changes in AA precursor emissions (ALL minus SSTGHG). Thick black lines highlight regions where the changes are statistically significant at the $90 \%$ confidence level, based on a two-tailed Student's $t$-test. The thick red boxes highlight Northeast Asia.

inducing a weak cooling in Tmax, a weak warming in Tmin, and, therefore, a decrease in DTR, over Northeast Asia (Figs. $7 \mathrm{~g}-\mathrm{i})$. The decrease in Tmax was mainly due to the increase in cloud cover locally, and this will be discussed in more detail in section 5.2. In contrast, the direct impacts of changes in aerosols led to an increase in Tmax over regions extending from Eastern Europe to Northeast Asia, while aerosols induced little change in Tmin. As a result, the changes in aerosols induced a significant increase in DTR over Eastern Europe and Northeast Asia. Therefore, weak changes in DTR over Northeast Asia in response to changes in all forcings is due to the compensating impacts from changes in GHG and SST/SIE (reducing DTR) and the impacts from changes in aerosols (enhancing DTR).

The spatial distributions of the responses in the frequencies of SU and TR are illustrated in Fig. 8. In response to changes in all forcings (Figs. 8a and b), the model reproduced both the pattern and magnitude of the frequency increases in SU and TR shown in observations over Northeast Asia (Figs. $3 \mathrm{f}$ and $\mathrm{g}$ ). Figure 8 also indicates that changes in SST/SIE played an equally important role as changes in aerosols in the increase in the frequency of SU (Figs. 8c, e and g), while the increase in the frequency of TR was predominantly due to changes in SST/SIE (Figs. 8d, f and h). Consistent with increased local aerosol emissions, the frequency of SU and TR decreased over South, Southeast and East Asia (Figs. 8g and h).

A number of area-averaged changes in summer seasonal mean SAT and seasonal or annual changes in temperature extremes over Northeast Asia, for both observations and modelsimulated responses, are illustrated in Figs. 9 and 10. Quantitatively, the model-simulated changes in response to changes 
(a) Change in summer days (All)

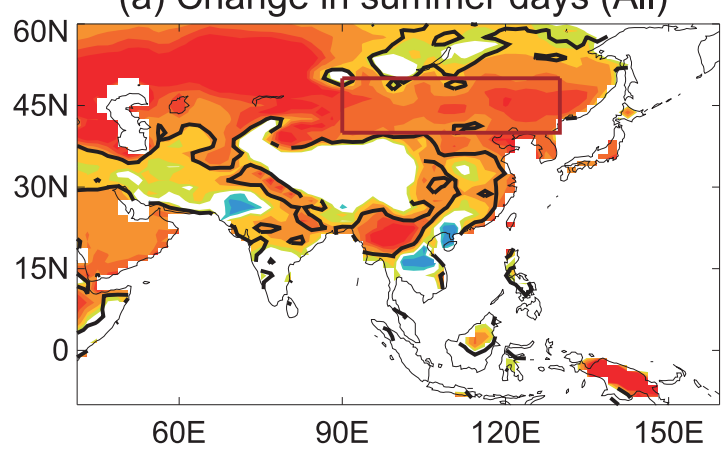

(c) Change in summer days (SST)

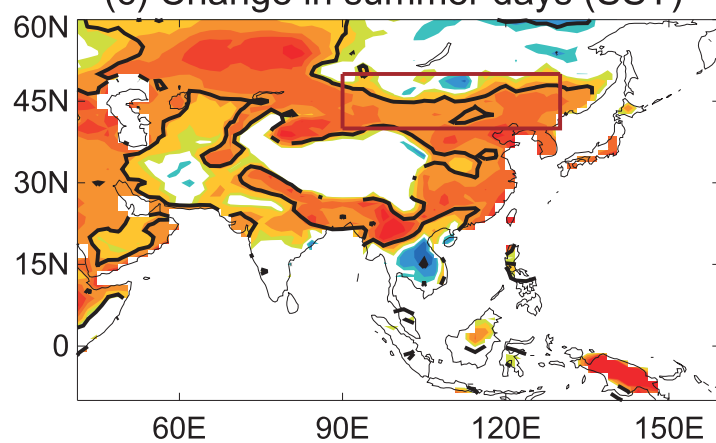

(e) Change in summer days (GHG)

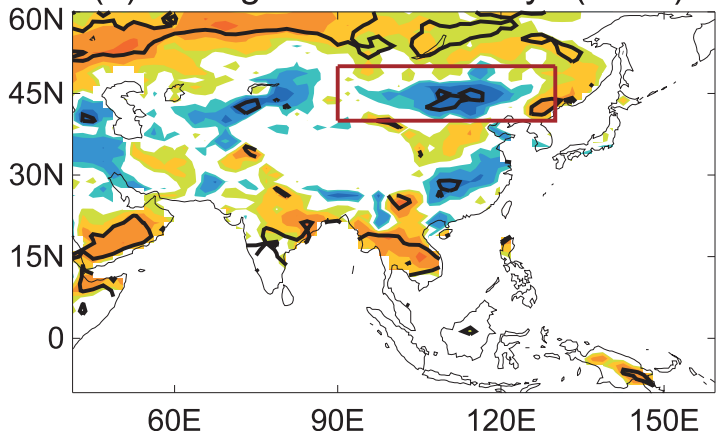

(g) Change in summer days (aerosols)

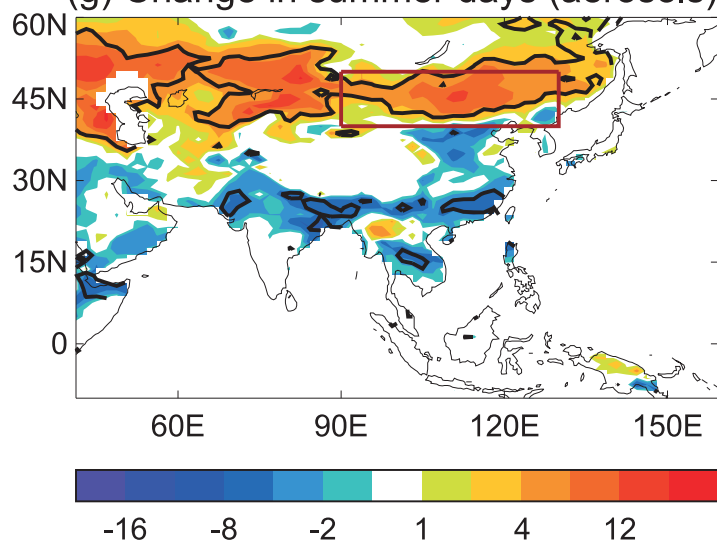

(b) Change in tropical nights (All)

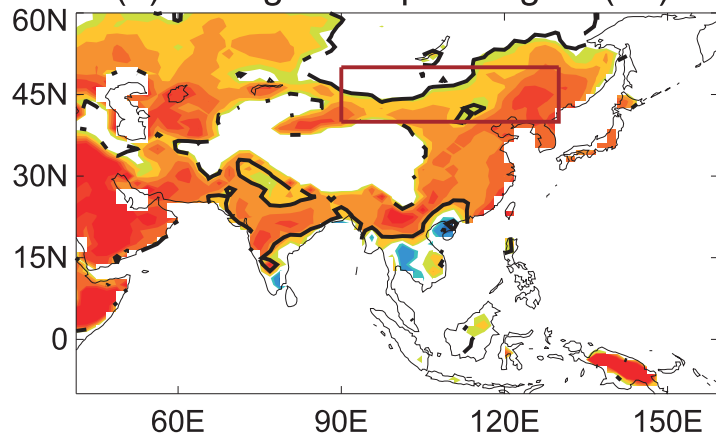

(d) Change in tropical nights (SST)

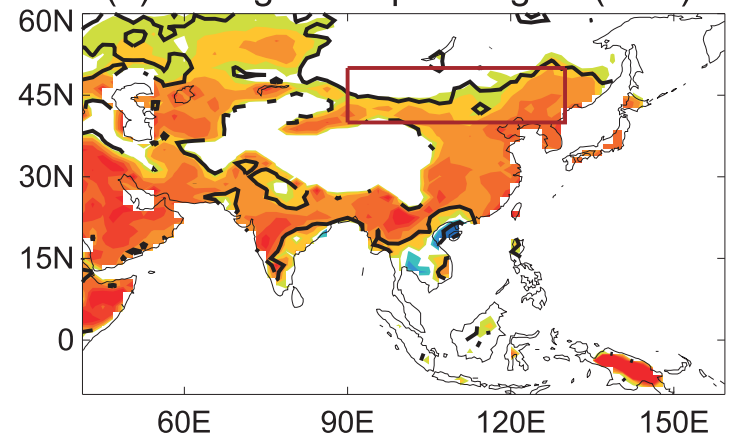

(f) Change in tropical nights (GHG)

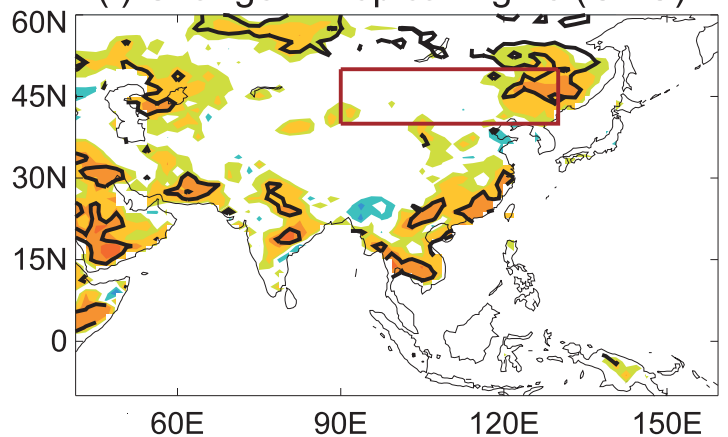

(h) Change in tropical nights (aerosols)

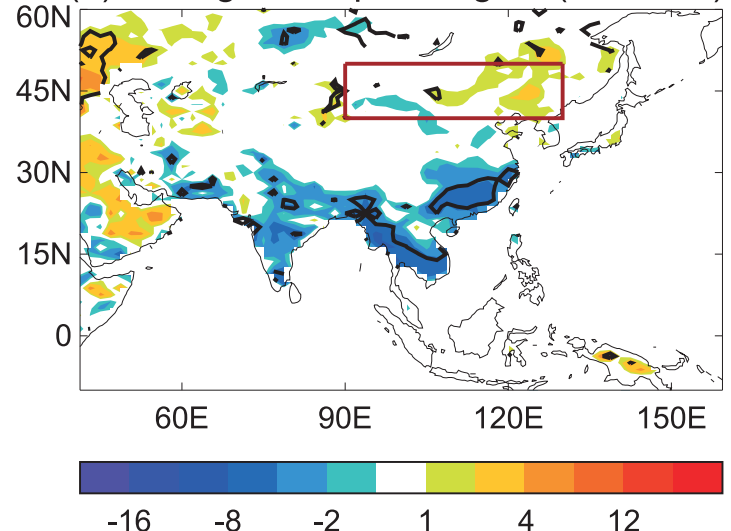

Fig. 8. Spatial patterns of responses for SU (left column) and TR (right) (units: $\mathrm{d} \mathrm{yr}^{-1}$ ): (a, b) response forced by changes in SST/SIE, GHG concentrations, and AA precursor emissions (ALL minus CONTROL); (c, d) response to changes in SST/SIE (SSTONLY minus CONTROL); (e, f) response to changes in GHG concentrations (SSTGHG minus SSTONLY); and ( $\mathrm{g}, \mathrm{h}$ ) response to changes in AA precursor emissions (ALL minus SSTGHG). Thick black lines highlight regions where the changes are statistically significant at the $90 \%$ confidence level, based on a two-tailed Student's $t$-test. The thick red boxes highlight Northeast Asia. 
in all forcings reproduced changes in summer seasonal areaaveraged SAT, Tmax and Tmin realistically, and this led to very small changes in the model-simulated DTR, similar to the observed change (Fig. 9a). The area-averaged increases in the frequency of SU and TR in response to changes in all forcings were also similar to observed changes, albeit weaker (Fig. 10a). In response to changes in all forcings, the model produced an area-averaged summer mean SAT change of $1.07^{\circ} \mathrm{C}$ over Northeast Asia, which was very close to the observed changes of $1.21^{\circ} \mathrm{C}$ to $1.27^{\circ} \mathrm{C}$. Furthermore, most of the surface warming signal $(76 \%$ change in SAT) was simulated in response to changes in SST/SIE. If the responses to individual forcings combined linearly, this implies that $21 \%$ of the SAT change was the response to changes in AA precursor emissions, and an additional $3 \%$ surface warming was the response to changes in GHG concentrations (Fig. 9b). Both changes in SST/SIE and AA led to an increase in Tmax, while the Tmin increase was predominantly due to changes in SST/SIE (Fig. 9b). The model results further suggest that the direct impact of changes in AA precursor emissions played a dominant role in the increase in TXx (Fig. 9b), and an equally important role as SST/SIE changes in the increase in the frequency of SU (Fig. 10b). Meanwhile, the increases in TNx and the frequency of TR were mainly due to the recent warm- ing of the ocean (Figs. 9b and 10b).

However, Fig. 9a indicates that the model response to changes in all forcings underestimated the changes in TXX and TNx. This underestimation might have been related to the weak land surface feedback in the model simulation, where the model response showed a weak change in summer mean precipitation (Fig. 6b) and therefore a small change in soil moisture (figure not shown), while observations indicate there was a drying trend over Northeast Asia (Fig. 2b). Previous work (e.g., Seneviratne et al., 2014) points out the role of land surface feedback associated with drying on the change in hot temperature extremes, but this land surface feedback over Northeast Asia in response to changes in all forcings was weak due to the compensating impacts that resulted from the changes in AA, as well as those from changes in SST/SIE and GHGs (Figs. 6d, f and h).

The significant role of changes in AA precursor emissions for changes in both summer mean SAT and temperature extremes over Northeast Asia is interesting. Given the fact that local AA precursor emissions over Asia are increasing and European and North American emissions are decreasing, which regional change of AA precursor emissions was responsible for those changes seen in the model experiment over Northeast Asia? The summer mean SAT changes in re-
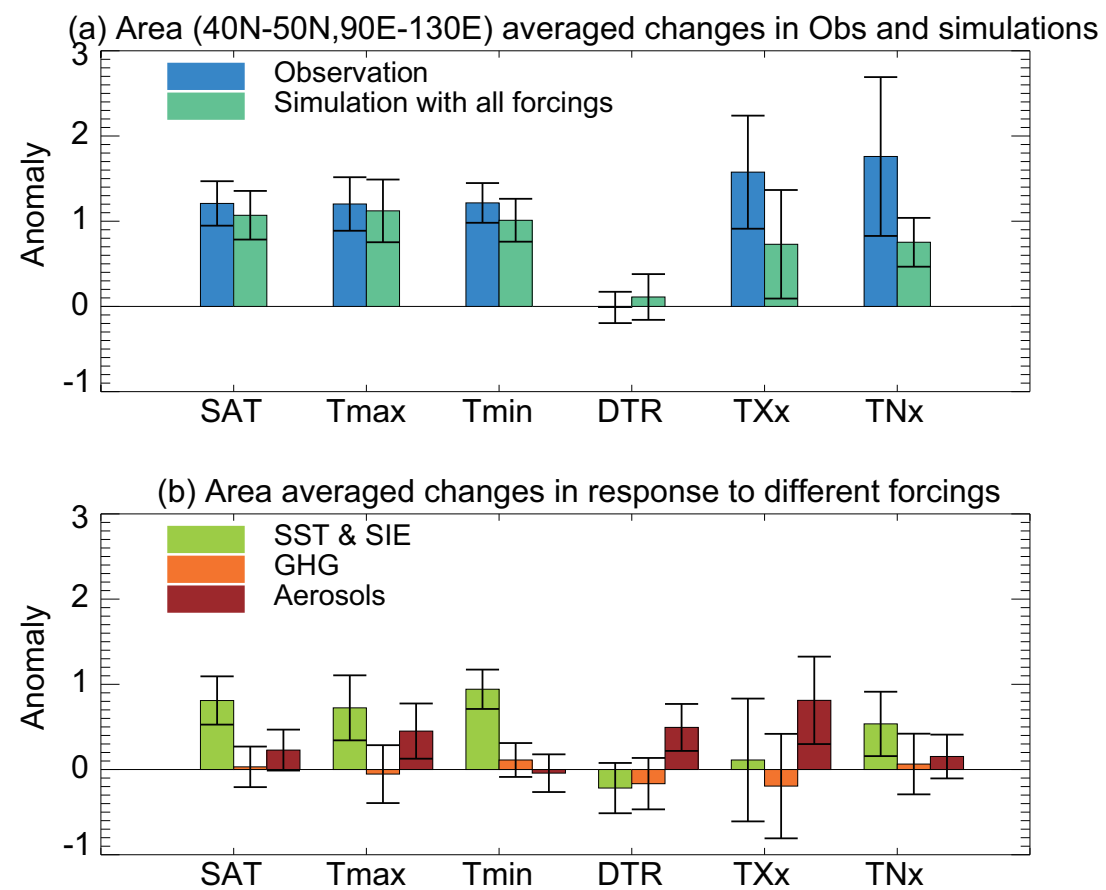

Fig. 9. Observed and model-simulated summer seasonal mean (JJAS) changes for SAT, Tmax, Tmin, and DTR, and annual changes in TXx and TNx over Northeast Asia (units: ${ }^{\circ} \mathrm{C}$ ): (a) observed changes (based on CRUTS3.2 and HadEX2) and simulated responses to changes in SST/SIE, GHG concentrations, and AA precursor emissions (ALL minus CONTROL) (colored bars indicate the central estimates and whiskers show the $90 \%$ confidence intervals, based on a two-tailed Student's $t$-test); (b) model-simulated changes in response to different forcings [SST \& SIE is the response to changes in SST/SIE (SSTONLY minus CONTROL); GHG is the response to GHG concentrations (SSTGHG minus SSTONLY); and AA is the response to changes in AA precursor emissions (ALL minus SSTGHG)]. 
(a) Area averaged changes in observations and model simulations

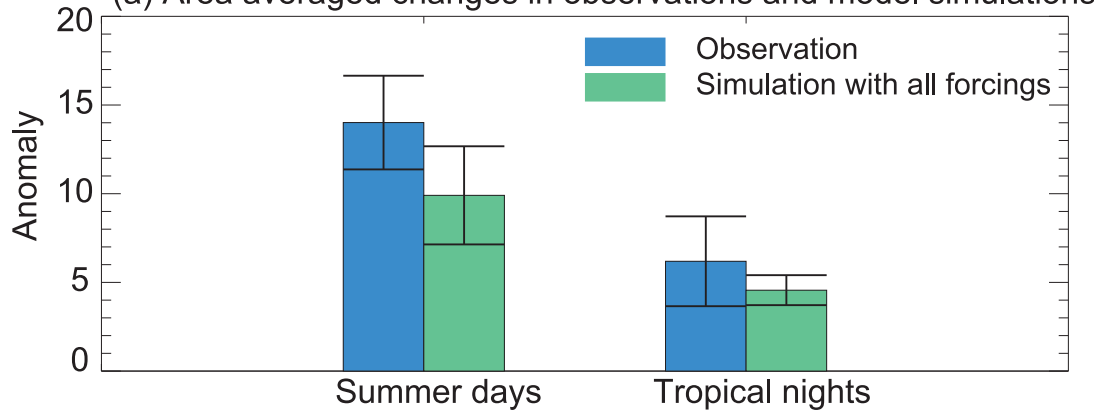

(b) Area averaged changes in response to different forcings

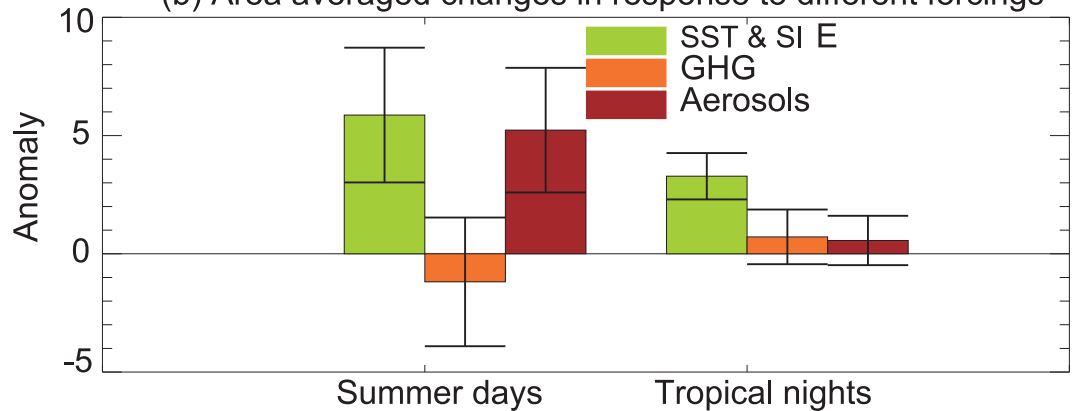

Fig. 10. (a) Observed (HadEX2) and simulated annual changes over Northeast Asia in response to changes in SST/SIE, GHG concentrations, and AA precursor emissions (ALL minus CONTROL) for the frequency of summer days and tropical nights (units: $\mathrm{d} \mathrm{yr}^{-1}$; colored bars indicate the central estimates and whiskers show the $90 \%$ confidence intervals, based on a two-tailed Student's $t$-test). (b) Model-simulated changes in response to different forcings [SST \& SIE is the response to changes in SST/SIE (SSTONLY minus CONTROL); GHG is the response to GHG concentrations (SSTGHG minus SSTONLY); and AA is the response to changes in AA precursor emissions (ALL minus SSTGHG)].

sponse to changes in AA precursor emissions shown in Fig. 6 indicate a band of positive SAT anomalies and reduced precipitation extending from Europe to Northeast Asia in the midlatitudes. Changes in AA precursor emissions also induced a band of increase in the seasonal mean Tmax, DTR (Figs. $7 \mathrm{j}$ and 1), TXx (figure not shown), and the frequency of SU (Fig. 8g). These results imply that changes over Northeast Asia in response to changes in AA precursor emissions are the downstream development of the European response to reduced emissions over Europe. They demonstrate a role of non-local AA changes for the summer mean climate over the Asian continent (e.g., Dong et al., 2016a) and associated changes in temperature extremes. The detailed physical processes responsible for the responses to changes in different forcings are discussed in next section.

\section{Physical processes responsible for the model-simulated changes induced by differ- ent forcings}

\subsection{Response induced by changes in SST/SIE}

The spatial distributions of the summer mean responses of some key variables induced by changes in SST/SIE are shown in Fig. 11, while the area-averaged changes over Northeast Asia in surface radiation, surface turbulent heat fluxes and some other key variables in response to changes in different forcings are given in Fig. 12. In response to SST/SIE changes, the most significant changes were the increased water vapor in the atmosphere over the ocean and Eurasian continent (Fig. 11a). The increased water vapor led to an increase in clear-sky net surface longwave (LW) radiation (Fig. 11b), which tended to warm the surface. However, Fig. 11c indicates that the net surface LW change was small, and this small net LW anomaly (Fig. 11c) likely reflected a balance between increased emissions from the warmer surface and increased absorption of radiation emitted by the warmer and moister atmosphere. In addition, the reduction in medium-level cloud (Fig. 11d) related to the increased stability over land in the midlatitudes (e.g., Dong et al., 2009) induced positive anomalies in the shortwave (SW) cloud radiative effect (CRE) (Fig. 11e). The reduction in the upward surface sensible heat flux over Northeast Asia (Fig. 11f), related to surface air warming more than the surface skin temperature (Fig. 12b), also contributed to the surface warming. In summary, it was the increased water vapor in the atmosphere over the Eurasian continent in the midlatitudes in response to SST/SIE changes that induced the surface warming over Northeast Asia, with fur- 
(a) Water vapor in JJAS (SST) (b) clear sky LW in JJAS (SST) (c) LW in JJAS (SST)
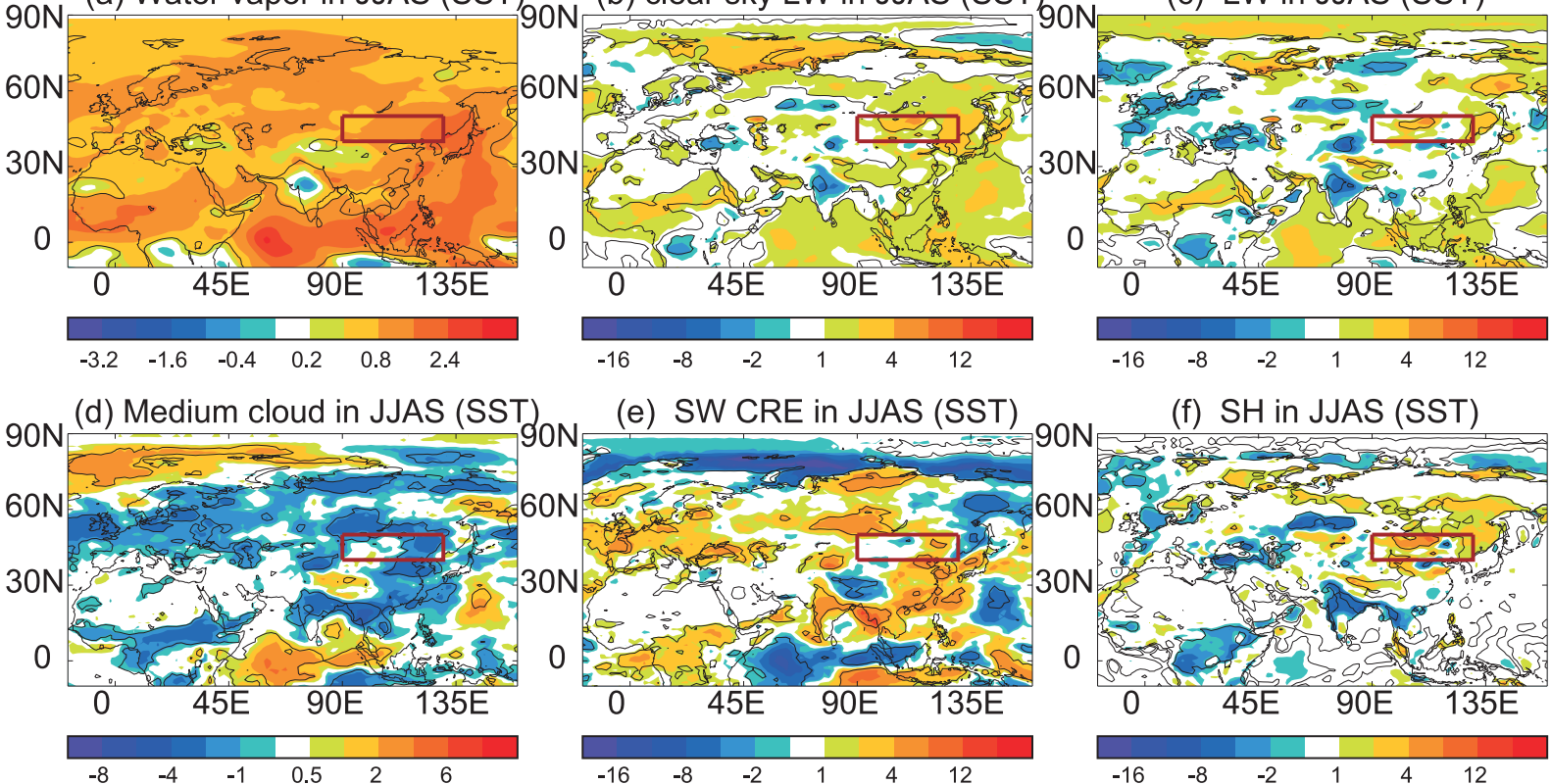

(f) $\mathrm{SH}$ in JJAS (SST)

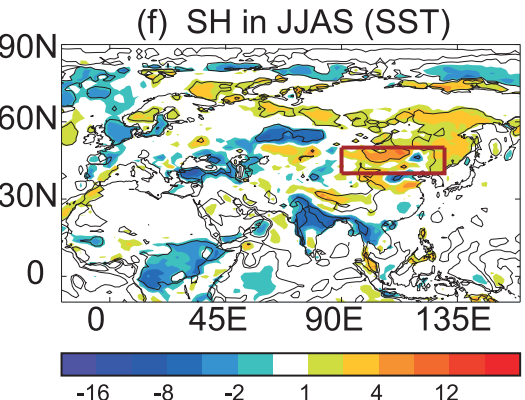

Fig. 11. Spatial patterns of responses to changes in SST/SIE (SSTONLY minus CONTROL): (a) column-integrated water vapor (units: $\mathrm{kg} \mathrm{m}^{-2}$ ); (b) clear-sky surface LW; (c) surface LW; (d) medium-level cloud cover (units: \%); (e) SW CRE; and (f) surface sensible heat flux. Radiation and fluxes are in $\mathrm{W} \mathrm{m}^{-2}$, and positive values mean downward. Radiation is the net component. Thin black lines highlight regions where the changes are statistically significant at the $90 \%$ confidence level, based on a two-tailed Student's $t$-test. The thick red boxes highlight Northeast Asia.

ther positive SW feedbacks through reduced cloud cover and decreased upward sensible heat flux related to the increase in the difference between the surface air and skin temperatures. This role of reduced cloud cover on summer surface warming over Eastern Europe agrees with the studies of Tang and Leng (2012) and Tang et al. (2012), who highlighted the role of decreased cloud cover in the recent observed changes in European hot summers. Our study further suggests that changes in SST/SIE might be partially responsible for the reduced summer cloud cover over Europe during recent decades.

\subsection{Response induced by changes in GHG forcing}

The spatial distributions of the summer mean responses of a number of key variables induced by changes in GHG forcing are given in Fig. 13. The main characteristics of surface energy changes over land in the midlatitudes of $30^{\circ}-$ $50^{\circ} \mathrm{N}$ indicate an increase in the net surface $\mathrm{LW}$ radiation (Fig. 13a). This increase was partly due to the increase in downward surface clear LW radiation (Fig. 13b; as expected for an increase in the Greenhouse Effect) and partly due to positive LW feedback resulting from increased water vapor in the atmosphere (Fig. 13c). In summary, it was the increased Greenhouse Effect that induced surface warming over Northeast Asia, with positive feedbacks from increased water vapor and reduced upward sensible heat flux (Fig. 13d), in response to GHG changes. The reduction in the upward sensible heat flux was the result of surface air warming being more than the surface skin temperature (Fig. 12b). The changes in surface SW radiation were closely related to changes in the SW CRE (Figs. 13e and f) as a consequence of increased total cloud cover (Fig. 12b) and water vapor (Fig. 13c), which tended to cool the surface over Northeast Asia.

\subsection{Response induced by changes in AA precursor emis- sions}

The spatial distributions of the summer mean responses of a number of key variables induced by changes in AA precursor emissions are illustrated in Fig. 14. Changes in sulfate aerosol optical depth (AOD) (Fig. 14a) indicate a decrease over Europe and an increase over South, Southeast, East Asia, and part of Northeast Asia, closely related to sulfur dioxide emission changes (e.g., Fig. 4b). Note that changes in AA in the model experiments included changes in sulfate, soot, biomass, and also other species (e.g., Bellouin et al., 2013). However, changes in soot AOD and biomass AOD (Figs. 14h and i) were much smaller than changes in sulfate AOD, suggesting that the responses to AA changes were predominantly due to changes in sulfate.

Local decreases in AOD over Europe led to significant regional surface warming over Western and Eastern Europe (Fig. 6g), through aerosol-radiation and aerosol-cloud interactions (e.g., Nabat et al., 2014; Dong et al., 2016a, 2016b). This in turn led to reduced precipitation (Fig. 6h) and a decrease in soil moisture over Europe (Fig. 14b). Associated with changes over Europe was the downstream extension of a significant decrease in water vapor in the atmosphere from Eastern Europe to Northeast Asia (Fig. 14c), resulting from decreased evaporation (Fig. 14g) related to the drying of soil (Fig. 14b). The reduction in column-integrated water vapor induced a decrease in atmospheric heating by SW absorption 
(a) Area averaged changes in response to different forcings

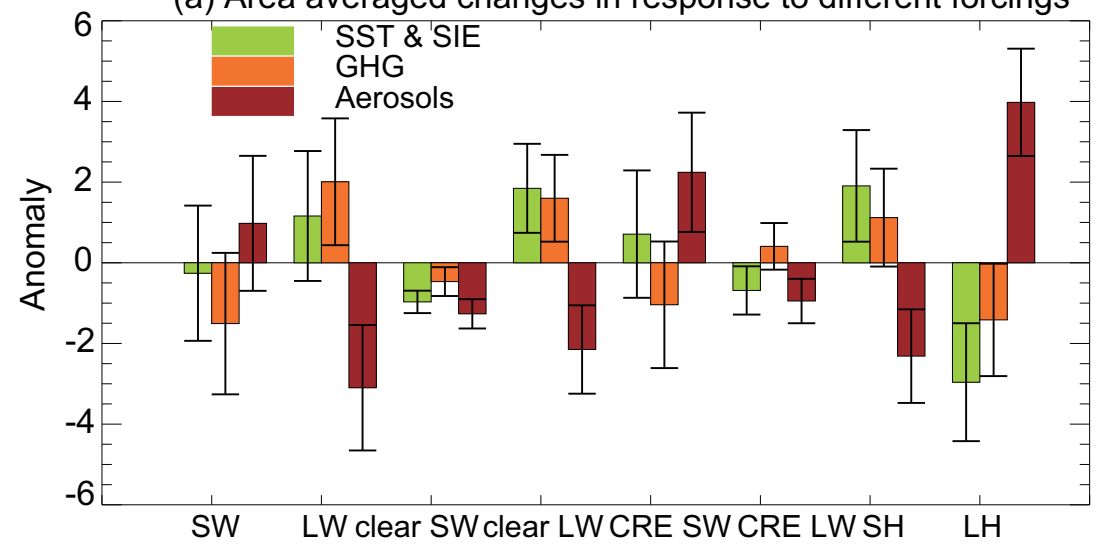

(b) Area averaged changes in response to different forcings

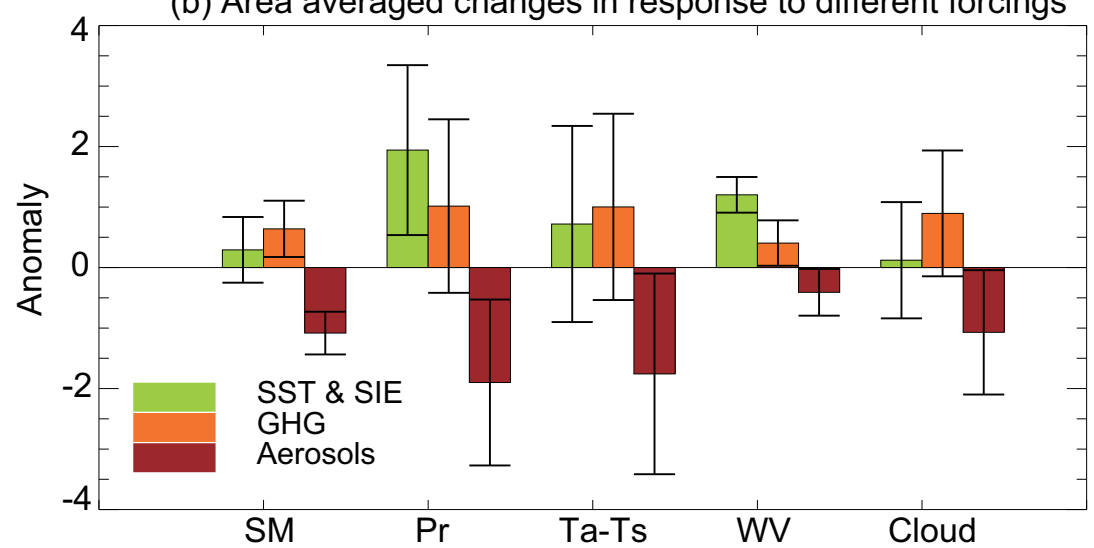

Fig. 12. Model-simulated summer seasonal mean (JJAS) changes over Northeast Asia for (a) net surface radiation and flux changes (units: $\mathrm{W} \mathrm{m}^{-2}$; positive values mean downward) and (b) soil moisture (SM; units: $\mathrm{kg} \mathrm{m}^{-2}$ ), precipitation (Pr; units: 0.1 $\mathrm{mm} \mathrm{d}^{-1}$ ), surface air and skin temperature difference (Ta-Ts; units: $0.1^{\circ} \mathrm{C}$ ), columnintegrated water vapor (WV; units: $\mathrm{kg} \mathrm{m}^{-2}$ ), and cloud fraction (units: \%) [SST \& SIE is the response to changes in SST/SIE (SSTONLY minus CONTROL); GHG is the response to GHG concentrations (SSTGHG minus SSTONLY); and AA is the response to changes in AA precursor emissions (ALL minus SSTGHG)]. The colored bars indicate the central estimates and whiskers show the $90 \%$ confidence intervals, based on a two-tailed Student's $t$-test.

(e.g., Mitchell et al., 1987, Dong et al., 2016b). This led to an increase in surface net clear-sky SW radiation, and therefore surface net SW radiation (Fig. 14d). The decrease in columnintegrated water vapor also induced a reduction in the LW radiative cooling of the atmosphere to the surface, leading to a decrease in net surface LW (Fig. 12a). The reduction in cloud cover associated with the decreased water vapor in the atmosphere led to a positive change in the SW CRE and a negative change in the LW CRE (Figs. 14e and f). This gave rise to larger changes in net surface $\mathrm{SW}$ and LW radiations than clear-sky net surface SW and LW radiations (Fig. 12a). The increased surface net SW radiation and reduced upward latent heat flux (Figs. 14d and g) led to a warming in SAT over the midlatitudes of $30^{\circ}-50^{\circ} \mathrm{N}$. These modelling results suggest that decreases in AA precursor emissions over Europe might also be partially responsible for the reduced summer cloud cover during recent decades over Eastern Europe (e.g., Tang and Leng, 2012; Tang et al., 2012), while landatmosphere interactions downstream drive responses of temperature and temperature extremes over Northeast Asia (Dai et al., 1999; Seneviratne et al., 2010; Mueller and Seneviratne, 2012; Schubert et al., 2014). The reduction in soil moisture led to reduced evapotranspiration and therefore resulted in decreased upward latent heat flux and increased upward sensible flux (Figs. 12a and 14g). The increased upward sensible heat flux in turn warmed the air, leading to an increase in evaporative demand, which tended to dry the soil further. This positive feedback between land surface and atmosphere led to a decrease in cloud cover and an increase in surface SW radiation, which again enhanced land surface drying. This positive feedback loop illustrates the importance of land surface processes in driving the regional responses of surface temperature and hot temperature extremes over Northeast Asia (Dai et al., 1999; Seneviratne et al., 2010; 


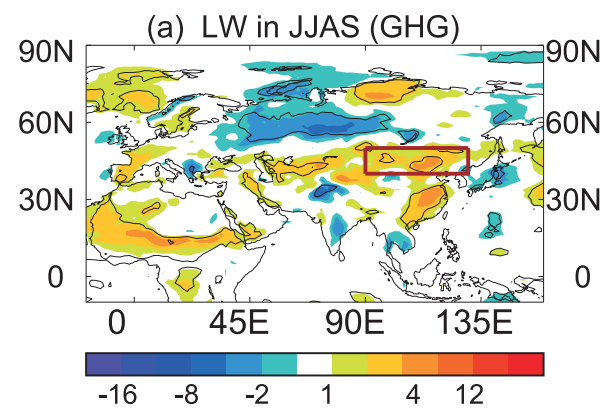

(b) clear sky LW in JJAS (GHG)

(c) Water vapor in JJAS (GHG)
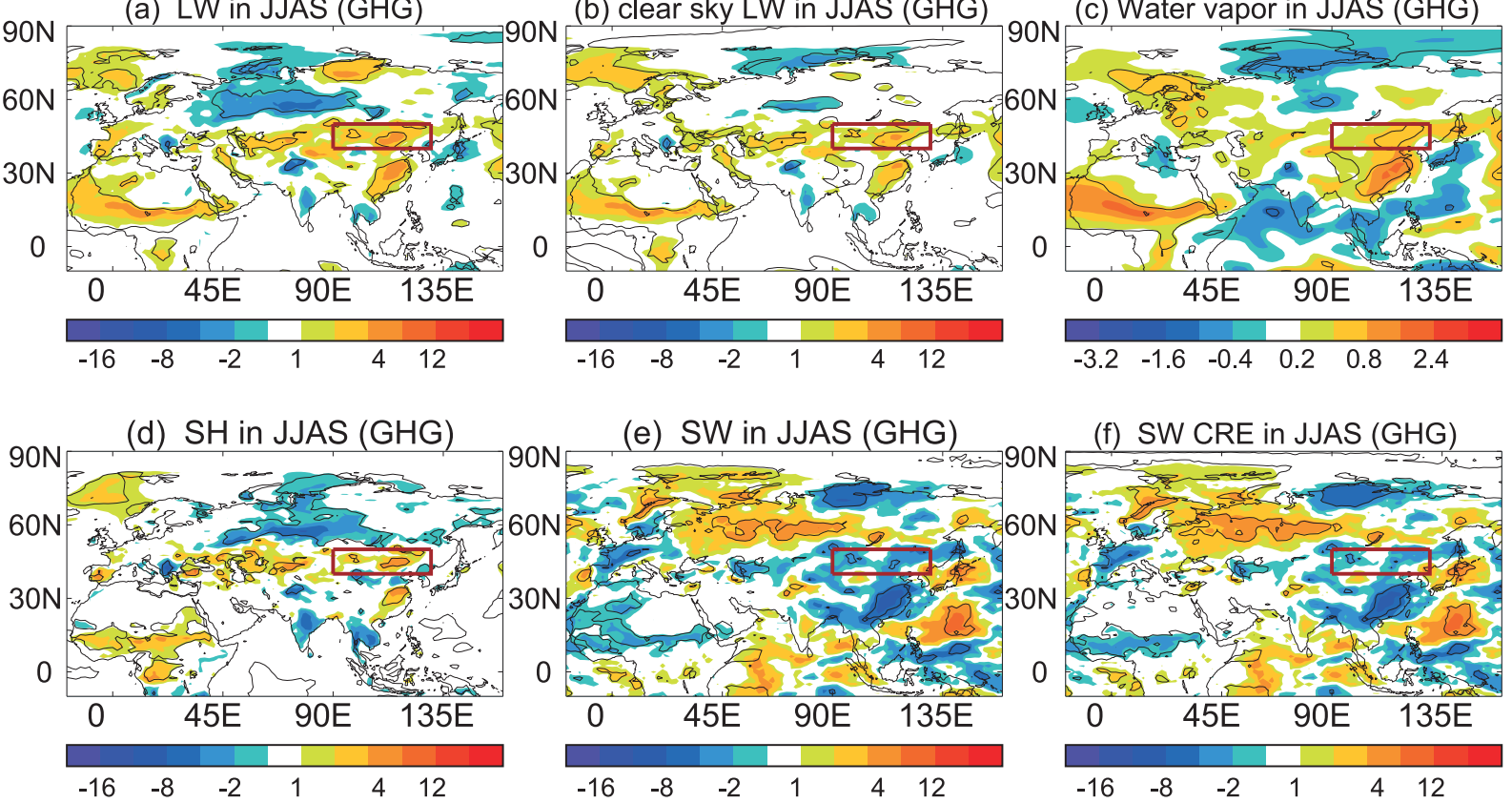

Fig. 13. Spatial patterns of responses to changes in GHG forcing (SSTGHG minus SSTONLY): (a) surface LW radiation; (b) clear-sky surface LW radiation; (c) column-integrated water vapor (units: $\mathrm{kg} \mathrm{m}^{-2}$ ); (d) surface sensible heat flux; (e) surface SW radiation; and (f) SW CRE. Radiation and fluxes are in $\mathrm{W} \mathrm{m}^{-2}$, and positive values mean downward. Radiation is the net component. Thin black lines highlight regions where the changes are statistically significant at the $90 \%$ confidence level, based on a two-tailed Student's $t$-test. The thick red boxes highlight Northeast Asia.

Mueller and Seneviratne, 2012; Schubert et al., 2014), and the resultant increases in Tmax, TXx and the frequency of SU, as well as the enhancement of DTR (Fig. 9b). In summary, the surface warming over Northeast Asia in response to changes in AA precursor emissions resulted from the increased net SW radiation due to the reduction in cloud cover and positive SW CRE related to tropospheric and surface drying associated with a coupled atmosphere-land response, rather than a direct impact of AA changes on cloud condensation nuclei and AOD. Also, the reduced upward latent heat flux tended to warm the surface and feed back positively to the reduction in cloud cover. The reduction in cloud cover in turn induced increases in Tmax, TXx and the frequency of SU.

\section{Conclusions}

This study investigated the drivers and physical processes involved in the abrupt summer mean surface warming over Northeast Asia and associated changes in temperature extremes since the mid-1990s. Firstly, we analyzed observations based on multiple data sets. Then, we carried out a set of numerical experiments using the atmospheric component of HadGEM3-A, to assess and quantify the relative roles of changes in three forcing factors [(1) SST/SIE; (2) anthropogenic GHG forcing through its direct impact; and (3) AA forcing through aerosol-radiation and aerosol-cloud interactions] in governing the changes in summer mean SAT and temperature extremes over Northeast Asia. No attempt was made to assess and quantify the anthropogenic contribution of changes in GHG concentrations and AA precursor emissions to the observed SST/SIE changes. The main findings and physical processes involved can be summarized as follows:

(1) Observations indicate that there was an abrupt increase in summer mean SAT over Northeast Asia in the mid1990s. The area-averaged SAT change over Northeast Asia in JJAS during the recent 16 years from 1996 to 2011, relative to the period $1964-93$, ranged from $1.21^{\circ} \mathrm{C}$ to $1.27^{\circ} \mathrm{C}$, from four data sets. Accompanying the abrupt increase in the summer mean SAT was a decrease in local precipitation.

(2) Also accompanying the abrupt increase in summer mean SAT were rapid changes in a number of temperature extremes. Specifically, there was a rapid increase in JJAS mean Tmax, Tmin, and in TXx and TNx over Northeast Asia, while the change in DTR was relatively small.

(3) Observational analysis also revealed a rapid increase (by 14 and 6 days, respectively) in the frequency of SU and TR over Northeast Asia since the mid-1990s.

(4) The model experiment forced by changes in SST/SIE and anthropogenic (GHG and AA) forcings together, relative to CONTROL, reproduced the general patterns of observed summer mean SAT changes and changes in temperature extremes over Northeast Asia. Changes in SST/SIE explained $76 \%$ of the area-averaged SAT signal over Northeast Asia, with $21 \%$ and $3 \%$ of the surface warming signal explained by the direct impacts of changes in AA precursor emissions and GHG concentrations, respectively. However, the precipitation responses to changes in all forcings were small, related to the compensating impacts from changes in SST/SIE and 


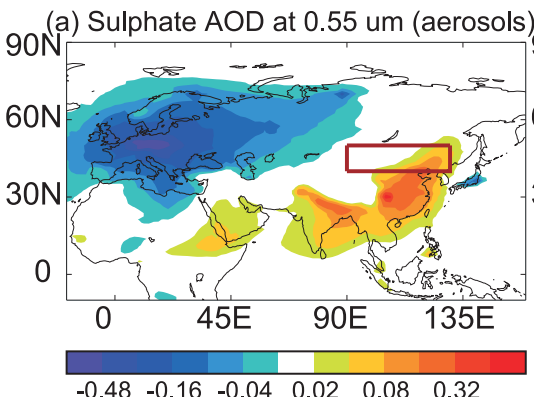

(b) Soil moisture (aerosols)

(c) Water vapor (aerosols)

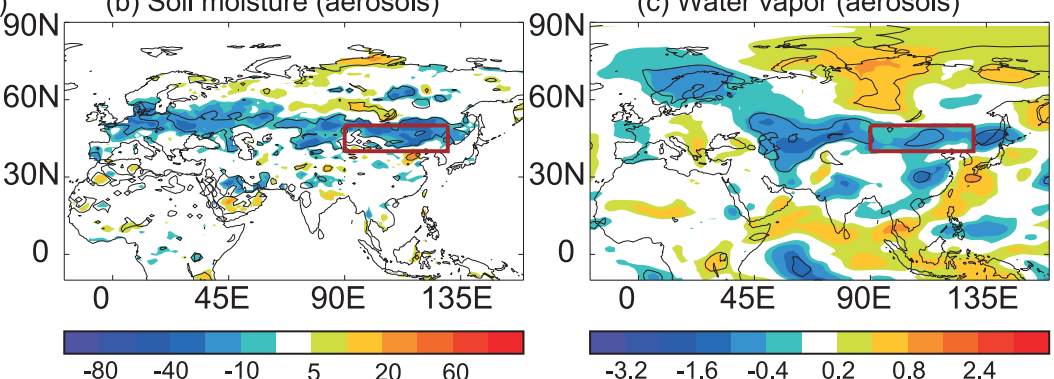

(d) SW (aerosols)

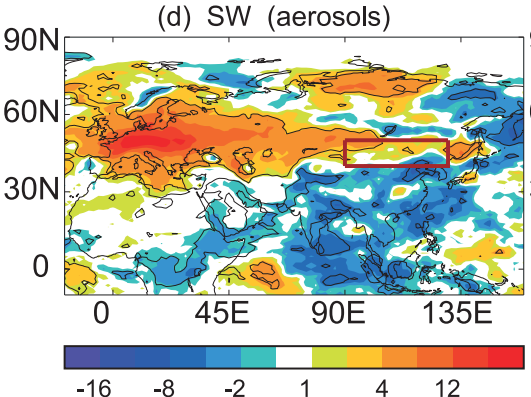

(e) Total cloud cover (aerosols)

(f) SW CRE (aerosols)
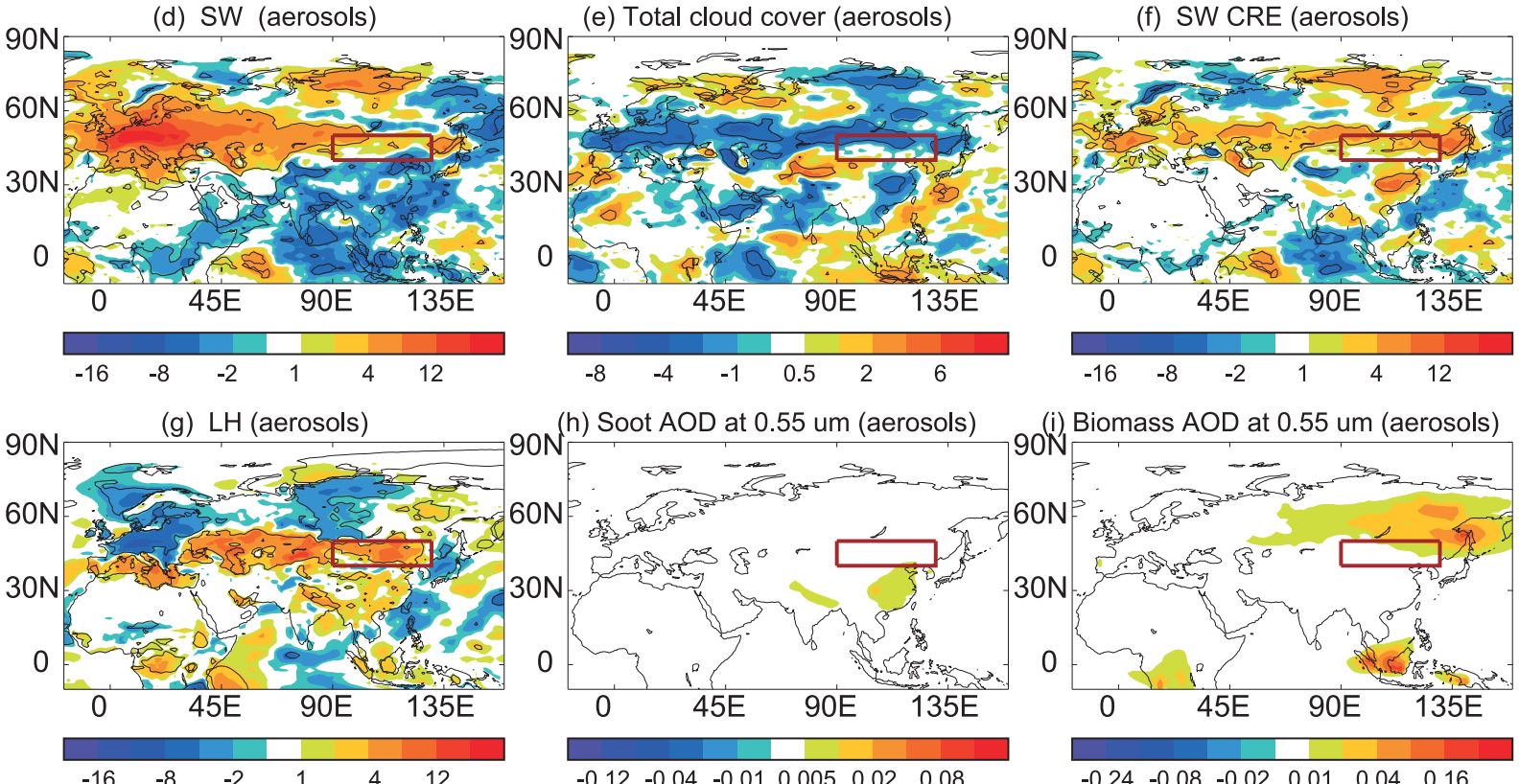

Fig. 14. Spatial patterns of responses to changes in aerosols (ALL minus SSTGHG): (a) sulfate AOD at 0.55 um; (b) soil moisture (units: $\mathrm{kg} \mathrm{m}^{-2}$ ), (c) column-integrated water vapor (units: $\mathrm{kg} \mathrm{m}^{-2}$ ); (d) surface SW radiation; (e) total cloud cover (units: $\%$ ); (f) SW CRE; (g) surface latent heat flux; (h) soot AOD at 0.55 um; and (i) biomass AOD at 0.55 um. Radiation and fluxes are in $\mathrm{W} \mathrm{m}^{-2}$, and positive values mean downward. Radiation is the net component. Thin black lines in (b-g) highlight regions where the changes are statistically significant at the $90 \%$ confidence level, based on a two-tailed Student's $t$-test. The thick red boxes highlight Northeast Asia.

AA, thus precluding a definitive attribution regarding recent precipitation changes over Northeast Asia.

(5) The direct impact of the changes in AA precursor emissions, through aerosol-radiation and aerosol-cloud interactions, mainly related to the reduction in emissions over Europe, played a dominant role in the increase in TXx, and an equally important role as SST/SIE changes in the increase in the frequency of SU through the reduction in cloud cover, related to coupled atmosphere-land surface feedbacks, rather than through a direct impact of AA changes on cloud condensation nuclei and AOD.

(6) The relatively small change in DTR induced by changes in all forcings was due to the compensating impact from changes in GHG concentrations and SST/SIE (reducing the DTR related to increased water vapor in the atmosphere and the associated increase in cloud cover) and the impact from changes in aerosols (enhancing the DTR related to decreased water vapor in the atmosphere and the associated reduction in cloud cover).
Whilst each forcing factor led to summer mean surface warming and changes in temperature extremes over the Eurasian continent in the model simulations, the spatial patterns of the responses were different and possessed distinct features in each case. For example, changes in SST/SIE induced a more or less uniform summer mean surface warming, while changes in AA precursor emissions induced a band of warming and changes in temperature extremes in the midlatitudes extending from Europe downstream to Northeast Asia at the surface. The results of this study indicate that reduced cloud cover enhances surface warming in the midlatitudes over the Eurasian continent in response to changes in both AA precursor emissions and SST/SIE, through its impact on SW radiation at the surface. In response to changes in AA, the model results indicate a local positive feedback between surface warming and reduced cloud cover, precipitation, soil moisture, and evaporation. This mechanism is an important factor leading to local increases in summer mean Tmax, DTR, TXx, and the frequency of SU. The local change 
in cloud cover, in turn, is closely related to change in the hydrological cycle and land surface processes. These results strengthen the conclusion that a realistic representation of cloud and its radiative effect, as well as the hydrological cycle, in climate models, are fundamental to the credibility for using such models to predict responses to a change in anthropogenic climate forcing. In the near term (the next few decades), GHG concentrations will continue to rise and AA precursor emissions over North America and Europe will continue to decrease. The results of this study imply that the rapid summer surface warming and increases in hot temperature extremes over Northeast Asia since the mid-1990s will probably continue, or even enhance, in the near term.

Acknowledgements. This work was supported by the UKChina Research \& Innovation Partnership Fund through the Met Office Climate Science for Service Partnership (CSSP) of China, as part of the Newton Fund. BD and RTS were supported by the UK National Centre for Atmospheric Science-Climate (NCASClimate) at the University of Reading. The UD, PREC/L, GPCP, and GISTEMP observational datasets and NCEP-NCAR reanalysis data are available from NOAA/OAR/ESRL PSD, Boulder, Colorado, USA, via http://www.esrl.noaa.gov/psd/. The CRUTS3.21 data were provided by the British Atmospheric Data Centre via http://badc. nerc.ac.uk/browse/badc/cru/data/cru_ts/cru_ts_3.21/data/, and the HadISST data are available at http://www.metoffice.gov.uk/hadobs/. The authors would like to thank the two anonymous reviewers for their constructive suggestions and valuable comments on the earlier version of this paper.

Open Access. This article is distributed under the terms of the Creative Commons Attribution 4.0 International License (http://creativecommons.org/licenses/by/4.0/), which permits unrestricted use, distribution, and reproduction in any medium, provided you give appropriate credit to the original author(s) and the source, provide a link to the Creative Commons license, and indicate if changes were made.

\section{REFERENCES}

Adler, R. F., and Coauthors, 2003: The version-2 global precipitation climatology project (GPCP) monthly precipitation analysis (1979-Present). Journal of Hydrometeorology, 4, 11471167.

Andrews, T., 2014: Using an AGCM to diagnose historical effective radiative forcing and mechanisms of recent decadal climate change. J. Climate, 27, 1193-1209.

Bellouin, N., G. W. Mann, M. T. Woodhouse, C. Johnson, K. S. Carslaw, and M. Dalvi, 2013: Impact of the modal aerosol scheme GLOMAP-mode on aerosol forcing in the Hadley Centre Global Environmental Model. Atmospheric Chemistry and Physics, 13, 3027-3044, doi: 10.5194/acp-13-30272013.

Chen, M. Y., P. P. Xie, J. E. Janowiak, and P. A. Arkin, 2002: Global land precipitation: a 50-yr monthly analysis based on gauge observations. Journal of Hydrometeorology, 3, 249266.

Chen, W., and R.Y. Lu, 2014: A decadal shift of summer sur- face air temperature over the Northeast Asia around the mid1990s. Adv. Atmos. Sci., 31, 735-742, doi: 10.1007/s00376013-3154-4.

Christidis, N., and Coauthors, 2013: A new HadGEM3-A-based system for attribution of weather and climate-related extreme events. J. Climate, 26, 2756-2783.

Cowan, T., and W. Cai, 2011: The impact of Asian and non-Asian anthropogenic aerosols on 20th century Asian summer monsoon. Geophys. Res. Lett., 38, L11703, doi: 10.1029/2011gl 047268 .

Dai, A. G., K. E. Trenberth, and T. R. Karl, 1999: Effects of clouds, soil moisture, precipitation, and water vapor on diurnal temperature range. J. Climate, 12, 2451-2473.

Ding, Y. H., Z. Y. Wang, and Y. Sun, 2008: Inter-decadal variation of the summer precipitation in East China and its association with decreasing Asian summer monsoon. Part I: Observed evidences. International Journal of Climatology, $\mathbf{2 8}$ 1139-1161, doi: 10.1002/joc.1615.

Ding, Y. H., Y. Sun, Z. Y. Wang, Y. X. Zhu, and Y. F. Song, 2009: Inter-decadal variation of the summer precipitation in China and its association with decreasing Asian summer monsoon Part II: Possible causes. International Journal of Climatology, 29, 1926-1944, doi: 10.1002/joc.1759.

Donat, M. G., and Coauthors, 2013: Updated analyses of temperature and precipitation extreme indices since the beginning of the twentieth century: the HadEX2 dataset. J. Geophys. Res., 118, 2098-2118, doi: 10.1002/jgrd.50150.

Dong, B.-W., and R. Sutton, 2015: Dominant role of greenhouse gas forcing in the recovery of Sahel rainfall. Nature Climate Change, 5, 757-760, doi: 10.1038/nclimate2664.

Dong, B.-W., J. M. Gregory, and R. T. Sutton, 2009: Understanding land-sea warming contrast in response to increasing greenhouse gases. Part I: Transient adjustment. J. Climate, 22, 3079-3097.

Dong, B.-W., R. T. Sutton, E. J. Highwood, and L. J. Wilcox, 2016a: Preferred response of the East Asian summer monsoon to local and non-local anthropogenic sulphur dioxide emissions. Climate Dyn., 46, 1733-1751, doi: 10.1007/ s00382-015-2671-5.

Dong, B.-W., R. T. Sutton, and L. Shaffrey, 2016b: Understanding the rapid summer warming and changes in temperature extremes since the mid-1990s over Western Europe. Climate Dyn., doi: 10.1007/s00382-016-3158-8.

Feng, S., and Q. Hu, 2008: How the North Atlantic Multidecadal Oscillation may have influenced the Indian summer monsoon during the past two millennia. Geophys. Res. Lett., 35, L01707, doi: 10.1029/2007GL032484.

Folini, D., and M. Wild, 2015: The effect of aerosols and sea surface temperature on China's climate in the late twentieth century from ensembles of global climate simulations. J. Geophys. Res., 120, 2261-2279, doi: 10.1002/2014JD022851.

Gao, L. H., Z. W. Yan, and X. W. Quan, 2014a: Observed and SSTforced multidecadal variability in global land surface air temperature. Climate Dyn., 44, 359-369, doi: 10.1007/s00382014-2121-9.

Gao, Z. T., Z.-Z. Hu, B. Jha, S. Yang, J. S. Zhu, B. Z. Shen, and R. J. Zhang, 2014b: Variability and predictability of Northeast China climate during 1948-2012. Climate Dyn., 43, 787-804, doi: 10.1007/s00382-013-1944-0.

Guo, L., E. J. Highwood, L. C. Shaffrey, and A. G. Turner, 2013: The effect of regional changes in anthropogenic aerosols on rainfall of the East Asian summer monsoon. Atmospheric 
Chemistry and Physics, 13, 1521-1534.

Han, T. T., H. P. Chen, and H. J. Wang, 2015: Recent changes in summer precipitation in Northeast China and the background circulation. International Journal of Climatology, 35, 42104219.

Hansen, J., R. Ruedy, M. Sato, and K. Lo, 2010: Global surface temperature change, Rev. Geophys., 48, RG4004, doi: 10.1029/2010RG000345.

Harris, I., P. D. Jones, T. J. Osborn, and D. H. Lister, 2014: Updated high-resolution grids of monthly climatic observations - the CRU TS3.10 dataset. International Journal of Climatology, 34, 623-642, doi: 10.1002/joc.3711.

Hewitt, H. T., D. Copsey, I. D. Culverwell, C. M. Harris, R. S. R. Hill, A. B. Keen, A. J. McLaren, and E. C. Hunke, 2011: Design and implementation of the infrastructure of HadGEM3: The next-generation Met Office climate modelling system. Geoscientific Model Development, 4, 223-253.

Huang, R. H., Y. Liu, and T. Feng, 2013: Interdecadal change of summer precipitation over Eastern China around the late1990s and associated circulation anomalies, internal dynamical causes. Chinese Science Bulletin, 58, 1339-1349.

Kalnay, E., and Coauthors, 1996: The NCEP/NCAR 40-year reanalysis project. Bull. Amer. Meteor. Soc., 77, 437-472.

Kamae, Y., H. Shiogama, M. Watanabe, and M. Kimoto, 2014a: Attributing the increase in Northern Hemisphere hot summers since the late 20th century. Geophys. Res. Lett., 41, 51925199.

Kamae, Y., M. Watanabe, M. Kimoto, and H. Shiogama, 2014b: Summertime land-sea thermal contrast and atmospheric circulation over East Asia in a warming climate-Part II: Importance of $\mathrm{CO}_{2}$-induced continental warming. Climate Dyn., $\mathbf{4 3}$, 2569-2583, doi: 10.1007/s00382-014-2146-0.

Kosaka, Y., and S. P. Xie, 2013: Recent global-warming hiatus tied to equatorial Pacific surface cooling. Nature, 501, 403-407.

Kühn, T., and Coauthors, 2014: Climate impacts of changing aerosol emissions since 1996. Geophys. Res. Lett., 41, 47114718, doi: 10.1002/2014GL060349.

Kwon, M., J.-G. Jhun, and K.-J. Ha, 2007: Decadal change in East Asian summer monsoon circulation in the mid-1990s. Geophys. Res. Lett., 34, L21706, doi: 10.1029/2007GL031977.

Lamarque, J. F., and Coauthors, 2010: Historical (1850-2000) gridded anthropogenic and biomass burning emissions of reactive gases and aerosols: Methodology and application. Atmospheric Chemistry and Physics, 10, 7017-7039.

Legates, D. R., and C. J. Willmott, 1990a: Mean seasonal and spatial variability in global surface air temperature. Theor. Appl. Climatol., 41, 11-21.

Legates, D. R., and C. J. Willmott, 1990b: Mean seasonal and spatial variability in gauge-corrected, global precipitation. International Journal of Climatology, 10, 111-127.

Levine, R. C., and A. G. Turner, 2012: Dependence of Indian monsoon rainfall on moisture fluxes across the Arabian Sea and the impact of coupled model sea surface temperature biases. Climate Dyn., 38, 2167-2190, doi: 10.1007/s00382011-1096-z.

Li, J., W. J. Dong, and Z. W. Yan, 2012: Changes of climate extremes of temperature and precipitation in summer in eastern China associated with changes in atmospheric circulation in East Asia during 1960-2008. Chinese Science Bulletin, 57, 1856-1861, doi: 10.1007/s11434-012-4989-2.

Liu, Y., and J. C. H. Chiang, 2012: Coordinated abrupt weakening of the Eurasian and North African Monsoons in the 1960s and links to extratropical North Atlantic cooling. J. Climate, 25, 3532-3548, doi: 10.1175/JCLI-D-11-00219.1.

Lu, Z., Q. Zhang, and D. G. Streets, 2011: Sulfur dioxide and primary carbonaceous aerosol emissions in China and India, 1996-2010. Atmospheric Chemistry and Physics, 11, 98399864, doi: 10.5194/acp-11-9839-2011.

Martin, G. M., S. F. Milton, C. A. Senior, M. E. Brooks, S. Ineson, T. Reichler, and J. Kim, 2010: Analysis and reduction of systematic errors through a seamless approach to modeling weather and climate. J. Climate, 23, 5933-5957, doi: 10.1175/2010JCLI3541.1.

Mitchell, J. F. B., C. A. Wilson, and W. M. Cunnington, 1987: On $\mathrm{CO}_{2}$ climate sensitivity and model dependence of results. Quart. J. Roy. Meteor. Soc., 113, 293-322.

Mueller, B., and S. I. Seneviratne, 2012: Hot days induced by precipitation deficits at the global scale. Proceedings of the $\mathrm{Na}$ tional Academy of Sciences of the United States of America, 109, 12 398-12 403, doi: 10.1073/pnas.1204330109.

Nabat, P., S. Somot, M. Mallet, A. Sanchez-Lorenzo, and M. Wild, 2014: Contribution of anthropogenic sulfate aerosols to the changing Euro-Mediterranean climate since 1980. Geophys. Res. Lett., 41, 5605-5611, doi: 10.1002/2014GL060798.

Qi, L., and Y. Q. Wang, 2012: Changes in the observed trends in extreme temperatures over China around 1990. J. Climate, 25, $5208-5222$.

Qian, C. C., J.-Y. Yu, and G. Chen, 2014: Decadal summer drought frequency in China: the increasing influence of the Atlantic Multi-decadal Oscillation. Environmental Research Letters, 9, 124004.

Rayner, N. A., D. E. Parker, E. B. Horton, C. K. Folland, L. V. Alexander, D. P. Rowell, E. C. Kent, and A. Kaplan, 2003: Global analyses of sea surface temperature, sea ice, and night marine air temperature since the late nineteenth century. $J$. Geophys. Res., 108, 4407, doi: 10.1029/2002JD002670.

Ren, G. Y., G. L. Feng, and Z. W. Yan, 2010: Progresses in observation studies of climate extremes and changes in mainland China. Climatic and Environmental Research, 15, 337-353. (in Chinese with English abstract)

Rosenfeld, D., U. Lohmann, G. B. Raga, C. D. O'Dowd, M. Kulmala, S. Fuzzi, A. Reissell, M. O. Andreae, 2008: Flood or drought: How do aerosols affect precipitation? Science, 321, 1309-1313 doi: 10.1126/science.1160606.

Schubert, S. D., H. L. Wang, R. D. Koster, M. J. Suarez, and P. Y. Groisman, 2014: Northern Eurasian heat waves and droughts. J. Climate, 27, 3169-3207.

Seneviratne, S. I., T. Corti, E. L. Davin, M. Hirschi, E. B. Jaeger, I. Lehner, B. Orlowsky, and A. J. Teuling, 2010: Investigating soil moisture-climate interactions in a changing climate: a review. Earth-Science Reviews, 99, 125-161.

Seneviratne, S. I., M. G. Donat, B. Mueller, and L. V. Alexander, 2014: No pause in the increase of hot temperature extremes. Nature Climate Change, 4, 161-163, doi: 10.1038/nclimate2145.

Shen, X. J., B. H. Liu, G. D. Li, Z. F. Wu, Y. H. Jin, P. J. Yu, and D. W. Zhou, 2014: Spatiotemporal change of diurnal temperature range and its relationship with sunshine duration and precipitation in China. J. Geophys. Res., 119, 13 163-13 179, doi: 10.1002/2014JD022326.

Smith, S. J., J. van Aardenne, Z. Klimont, R. J. Andres, A. Volke, and S. D. Arias, 2011: Anthropogenic sulfur dioxide emissions: 1850-2005. Atmospheric Chemistry and Physics, 11, 1101-1116, doi: 10.5194/acp-11-1101-2011. 
Song, F. F., T. J. Zhou, and Y. Qian, 2014: Responses of East Asian summer monsoon to natural and anthropogenic forcings in the 17 latest CMIP5 models. Geophys. Res. Lett., 41, 596-603, doi: 10.1002/2013GL058705.

Sperber, K. R., H. Annamalai, I.-S. Kang, A. Kitoh, A. Moise, A. Turner, B. Wang, and T. Zhou, 2013: The Asian summer monsoon: an intercomparison of CMIP5 vs. CMIP3 simulations of the late 20th century. Climate Dyn., 41, 2711-2744, doi: 10.1007/s00382-012-1607-6.

Steinman, B. A., M. E. Mann, and S. K. Miller, 2015: Atlantic and Pacific multidecadal oscillations and Northern Hemisphere temperatures. Science, 347, 988-991, doi: 10.1126/science. 1257856.

Sun, Y., X. B. Zhang, F. W. Zwiers, L. C. Song, H. Wan, T. Hu, H. Yin, and G. Y. Ren, 2014: Rapid increase in the risk of extreme summer heat in Eastern China. Nature Climate Change, 4, 1082-1085, doi: 10.1038/nclimate2410.

Tang, Q. H., and G. Y. Leng, 2012: Damped summer warming accompanied with cloud cover increase over Eurasia from 1982 to 2009. Environmental Research Letters, 7, 014004, doi: 10.1088/1748-9326/7/1/014004

Tang, Q. H., G. Y. Leng, and P. Y. Groisman, 2012: European hot summers associated with a reduction of cloudiness. J. Climate, 25, 3637-3644.

Trenberth, K. E., J. T. Fasullo, G. Branstator, and A. S. Phillips, 2014: Seasonal aspects of the recent pause in surface warming. Nature Climate Change, 4, 911-916, doi: 10.1038/nclimate2341.

Twomey, S., 1977: The influence of pollution on the shortwave albedo of clouds. Journal of Atmospheric Sciences, 34, 11491154.

Ueda, H., Y. Kamae, M. Hayasaki, A. Kitoh, S. Watanabe, Y. Miki, and A. Kumai, 2015: Combined effects of recent Pacific cooling and Indian Ocean warming on the Asian monsoon. Nature Communications, 6, 8854, doi: 10.1038/ncomms9854.

Urabe, Y., and S. Maeda, 2014: The relationship between Japan's recent temperature and decadal variability. SOLA, 10, 176-
179, doi: 10.2151/sola.2014-037.

Wang, H. J., and Coauthors, 2012: Extreme climate in China: Facts, simulation and projection. Meteor. Z., 21, 279-304.

Wang, T., H. J. Wang, O. H. Otterå, Y. Q. Gao, L. L. Suo, T. Furevik, and L. Yu, 2013: Anthropogenic agent implicated as a prime driver of shift in precipitation in eastern China in the late 1970s. Atmospheric Chemistry and Physics, 13, 12 43312 450, doi: 10.5194/acpd-13-11997-2013.

Wei, K., and W. Chen, 2011: An abrupt increase in the summer high temperature extreme days across China in the mid1990s. Adv. Atmos. Sci., 28, 1023-1029.

Wen, Q. H., X. B. Zhang, Y. Xu, and B. Wang, 2013: Detecting human influence on extreme temperatures in China. Geophys. Res. Lett., 40, 1171-1176, doi: 10.1002/grl.50285.

Wilcox, L. J., B. Dong, R. T. Sutton, and E. J. Highwood, 2015: The 2014 hot, dry summer in northeast Asia. Bull. Amer. Metero. Soc., 96, S105-S110.

Yang, S. L., J. M. Feng, W. J. Dong, and J. M. Chou, 2014: Analyses of extreme climate events over China based on CMIP5 historical and future simulations. Adv. Atmos. Sci., 31, 12091220, doi: 10.1007/s00376-014-3119-2.

You, Q. L., J. Z. Min, Y. Jiao, M. Sillanpää, and S. C. Kang, 2015: Observed trend of diurnal temperature range in the Tibetan Plateau in recent decades. International Journal of Climatology, 36, 2633-2643, doi: 10.1002/joc.4517.

Zhang, L. X., and T. J. Zhou, 2015: Drought over East Asia: a review. J. Climate, 28, 3375-3399, doi: 10.1175/JCLI-D-1400259.1 .

Zhao, P., S. Yang, and R. C. Yu, 2010: Long-term changes in rainfall over eastern China and large-scale atmospheric circulation associated with recent global warming. J. Climate, 23, 1544-1562, doi: 10.1175/2009JCLI2660.1.

Zhao, P., P. Jones, L. J. Cao, Z. W. Yan, S. Y. Zha, Y. N. Zhu, Y. Yu, and G. L. Tang, 2014: Trend of surface air temperature in eastern China and associated large-scale climate variability over the last 100 years. J. Climate, 27, 4693-4703, doi: 10.1175/JCLI-D-13-00397.1. 